Article

\title{
Combustion Analysis of a Diesel Engine during Warm up at Different Coolant and Lubricating Oil Temperatures
}

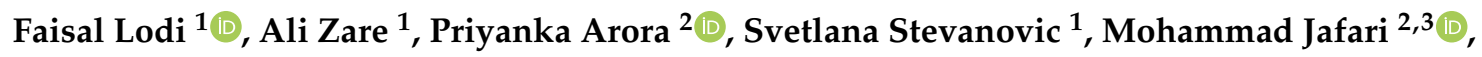 \\ Zoran Ristovski ${ }^{2}$, , Richard J. Brown ${ }^{3}$ and Timothy Bodisco ${ }^{1, *(\mathbb{C}}$ \\ 1 School of Engineering, Deakin University, 75 Pigdons Rd, Geelong, VIC 3216, Australia; \\ flodi@deakin.edu.au (F.L.); ali.zare@deakin.edu.au (A.Z.); svetlana.stevanovic@deakin.edu.au (S.S.) \\ 2 International Laboratory for Air Quality and Health (ILAQH), Queensland University of Technology, \\ 2 George St, Brisbane, QLD 4000, Australia; p2.arora@hdr.qut.edu.au (P.A.); \\ mohammad.jafari@qut.edu.au (M.J.); z.ristovski@qut.edu.au (Z.R.) \\ 3 Biofuel Engine Research Facility, Queensland University of Technology, 2 George St, \\ Brisbane, QLD 4000, Australia; richard.brown@qut.edu.au \\ * Correspondence: t.bodisco@deakin.edu.au; Tel.: +61-3-5247-9496
}

Received: 22 June 2020; Accepted: 27 July 2020; Published: 1 August 2020

\begin{abstract}
A comprehensive analysis of combustion behaviour during cold, intermediately cold, warm and hot start stages of a diesel engine are presented. Experiments were conducted at $1500 \mathrm{rpm}$ and $2000 \mathrm{rpm}$, and the discretisation of engine warm up into stages was facilitated by designing a custom drive cycle. Advanced injection timing, observed during the cold start period, led to longer ignition delay, shorter combustion duration, higher peak pressure and a higher peak apparent heat release rate (AHRR). The peak pressure was $\sim 30 \%$ and $20 \%$ and the AHRR was $\sim 2$ to $5 \%$ and $\pm 1 \%$ higher at $1500 \mathrm{rpm}$ and $2000 \mathrm{rpm}$, respectively, during cold start, compared to the intermediate cold start. A retarded injection strategy during the intermediate cold start phase led to shorter ignition delay, longer combustion duration, lower peak pressure and lower peak AHRR. At $2000 \mathrm{rpm}$, an exceptional combustion behaviour led to a $\sim 27 \%$ reduction in the AHRR at $25 \%$ load. Longer ignition delays and shorter combustion durations at $25 \%$ load were observed during the intermediately cold, warm and hot start segments. The mass fraction burned (MFB) was calculated using a single zone combustion model to analyse combustion parameters such as crank angle (CA) at 50\% MFB, AHRR@CA50 and CA duration for $10-90 \%$ MFB.
\end{abstract}

Keywords: diesel engine cold start; peak pressure timing; peak AHRR; mass fraction burned; start of combustion; end of combustion; combustion duration; ignition delay

\section{Introduction}

Transportation systems are of vital importance to the growth and development of a nation. In Australia, the transport sector has grown by approximately $63 \%$ over the last decade, according to the 2017 estimates from the Australian Department of Environment and Energy [1]. Owing to the high fuel conversion efficiency, diesel engines are a popular choice in the transportation sector and therefore a high portion of the vehicles in the market are diesel engines [1]. The combustion process in a diesel engine is three-dimensional, complex, unsteady and heterogeneous, primarily depending upon the engine operating conditions, in addition to the combustion chamber, the fuel and the fuel injection system [2]. Unlike gasoline engines, a diesel engine uses fuel injectors to inject fuel directly into the combustion chamber. Since ignition in a diesel engine occurs by autoignition, the in-cylinder temperature and pressure before fuel injection are important combustion parameters. 
This is particularly relevant to diesel engine cold start operation [2,3], as it may lead to partial or complete misfire if the cylinder temperature is below the threshold self-ignition temperature of the fuel.

Engine cold start operation is an unavoidable part of the daily driving for a significant number of vehicles in cities. Therefore, engine behaviour during the engine warm-up period is of significant importance. During the first few minutes of cold engine operation, factors such as poor mixture preparation, variations in the air-to-fuel ratio (AFR) and combustion instability cause large cyclic variability, which can adversely affect the engine performance and emissions $[4,5]$. The high combustion instability during engine cold start may result in a significant decrease in the engine thermal efficiency and increase in hydrocarbon (HC) emissions [6]. The difficulty of starting diesel engines, due to combustion instability at low temperatures, causes the engine to misfire, and it may continue to misfire during cold start [5]. Henein [5] referred to this phenomenon as an 8-stroke and a 12-stroke cycle operation, if the misfires occurs once or twice, respectively. A successful cold starting event involves minimum assistance from the starter motor and a low number of cranking cycles to reach the idling speed and continue to run without any misfires [3].

It is important that the injected fuel makes maximum contact with the available air in the cylinder to ensure complete combustion. The heterogeneous mixture in a diesel engine consist of unevenly distributed regions of rich and lean mixture, which may lead to higher HC emissions, due to incomplete combustion or misfires [2,7]. Similarly, higher in-cylinder pressure and temperature, which are primarily affected by the injection timings, may lead to higher nitrogen oxides (NOx) formation $[2,7,8]$. Therefore, combustion behaviour, due to its influence on the engine performance, has been a subject of study for more than the last three decades. A number of investigations can be found on the combustion process of the diesel engines, such as those described by the authors of [9-12]. During the combustion process, the mass fraction burned (MFB) and the heat release rate (HRR) estimations are important, as they reflect upon the completeness of combustion [2]. The MFB reflects on the amount of fuel burned, while the HRR is indicative of the rate of burning throughout the combustion process [9]. Other combustion parameters considered important are ignition delay, start of combustion (SOC) and combustion duration, which have been investigated in studies such as those described by the authors of $[11,13]$.

According to the directive of the European Union (EU) Commission (2012/46/EU), cold start is defined as the period from the engine start either for the first $5 \mathrm{~min}$ or until the engine coolant temperature reaches $70{ }^{\circ} \mathrm{C}$, whichever occurs first [14]. However, it has been shown that even after this defined period, the engine is still warming up [15], leading to combustion inefficiencies. Most combustion studies on diesel engines, to date, have dedicated themselves to investigating the steady state operating conditions (when the engine is thermally stable), with only a few researchers investigating combustion characteristics under cold start conditions, such References $[5,6,16]$. However, to date, none of the studies in the literature have systematically analysed the combustion behaviour over the entire engine warm-up period to investigate the effects of engine temperature. Therefore, it is important that systematic and detailed combustion investigations are carried out to understand cold and intermediately cold start combustion behaviour in a diesel engine. Owing to the limited research in the diesel engine cold start combustion processes, this study was designed to gain more insight into the combustion behaviour of a six-cylinder, turbocharged, common rail diesel engine, during cold, intermediately cold and hot start operation. The objective of this research was to conduct a systematic investigation into the combustion behaviour of an experimental engine by discretising the engine run into various stages of warm up: Stage 1 was cold start according to the EU regulation [14]; Stage 2 was not cold start (as per the regulation), however, in this stage, both the coolant and oil temperatures were still increasing; in Stage 3, the engine coolant was optimum, however, the lubricating oil temperature was still increasing; and in Stage 4, the coolant and oil temperatures were optimum and the engine was completely warmed up.

This study aimed to analyse the effects of each stage of engine warm up on a wide range of engine combustion parameters. Given that the fundamental research would be limited using a conventional 
drive cycle such as the World-Harmonised Transient Cycle (WHTC) or the European Stationary Cycle (ESC) due to their patterns, this study used a custom designed drive cycle. The drive cycle in this study included frequent engine stop/start and abrupt load changes and the replication of short steady state periods, ensuring that the effects of engine warm up on the combustion parameters could be studied fundamentally.

\section{Experimental Facility}

The current study employed a Euro III, six-cylinder, turbocharged, common rail, Cummins diesel engine. The engine was coupled to an electronically controlled water brake dynamometer to control the engine speed and load. A piezoelectric pressure transducer (manufactured by Kistler having a sensitivity of approximately 20 pC/bar), a crank angle (CA) sensor (manufactured by Kistler having a resolution of $0.5 \mathrm{CA}$ degrees) and a fuel injector signal were connected to an analogue to digital converter [17]. The piezoelectric transducer was capable of measuring the voltage, rather than the pressure and the voltage, having a linear dependency to the in-cylinder pressure [18,19]. The engine specifications are shown in Table 1.

Table 1. Specifications of the experimental engine utilised in the current study [17].

\begin{tabular}{cc}
\hline Model & Cummins ISBe220 31 \\
\hline Cylinders & 6 in-line \\
Capacity & 5.91 \\
Fuel injection & High pressure common rail \\
Compression ratio & $17.3: 1$ \\
Maximum power $(\mathrm{kW})$ & $162 \mathrm{~kW} @ 2000 \mathrm{rpm}$ \\
Maximum torque $(\mathrm{Nm})$ & $820 \mathrm{Nm} @ 1500 \mathrm{rpm}$ \\
Aspiration & Turbocharged \\
Bore $\times$ stroke $(\mathrm{mm} \times \mathrm{mm})$ & $102 \times 120$ \\
Connecting rod $(\mathrm{mm})$ & 220 \\
Emissions standard & Euro III \\
\hline
\end{tabular}

\subsection{Experimental Procedure}

The experimental campaign was run in the Biofuel Engine Research Facility (BERF) at Queensland University of Technology (QUT). The experiments were conducted (with three repetitions) at an ambient temperature of $23{ }^{\circ} \mathrm{C} \pm 2{ }^{\circ} \mathrm{C}$ on a cold engine. The cold start experiments were performed after the engine was soaked overnight or forced cooled, as per the cold start regulation (EU Directive 2012/46/EU) [14]. Two engine speeds were selected for the experiments: $1500 \mathrm{rpm}$-the engine speed for rated torque, and $2000 \mathrm{rpm}$ - the engine speed for rated power. The experiments were performed over a custom designed cold and intermediately cold start drive cycle, programmed into the dynamometer control software.

\subsection{Experimental Drive Cycle}

The custom cold and intermediately cold start drive cycle was designed to include frequent engine stop/start and abrupt load changes. The experimental drive cycle was $1380 \mathrm{~s}$ long and was divided into eight engine run segments of $120 \mathrm{~s}$ each, with $60 \mathrm{~s}$ of engine stop periods between each segment. Each engine run segment was divided into four loads of $30 \mathrm{~s}$ each, with the order of the loads repeated in all segments. Selecting a 100\% load at the start of the engine run segment ensured that the maximum change in load occurred. Similarly, selecting $50 \%$ as the second load and $75 \%$ as the third load also ensured a significant (50\%) load change to occur, while the $25 \%$ load at the end of the segment was selected to prevent any potential harm to the engine, particularly to the turbocharger, as a lower load operation reduced the exhaust temperature to $150^{\circ} \mathrm{C}$ before the engine was turned off. At the start of each engine run segment, the engine was allowed to idle for $3 \mathrm{~s}$ before it was switched to the automated drive cycle operation and subjected to maximum load. Figure 1 shows the speed and 
load changes in the designed drive cycle for Segment 1. Further details about the experimental drive cycle have been described in Reference [20].

\section{— Engine Speed —— Engine load}

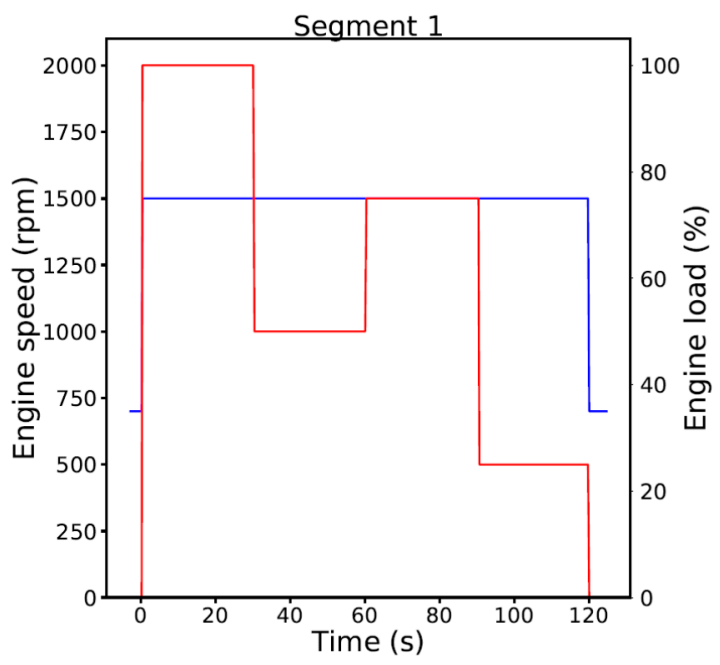

(a) $1500 \mathrm{rpm}$

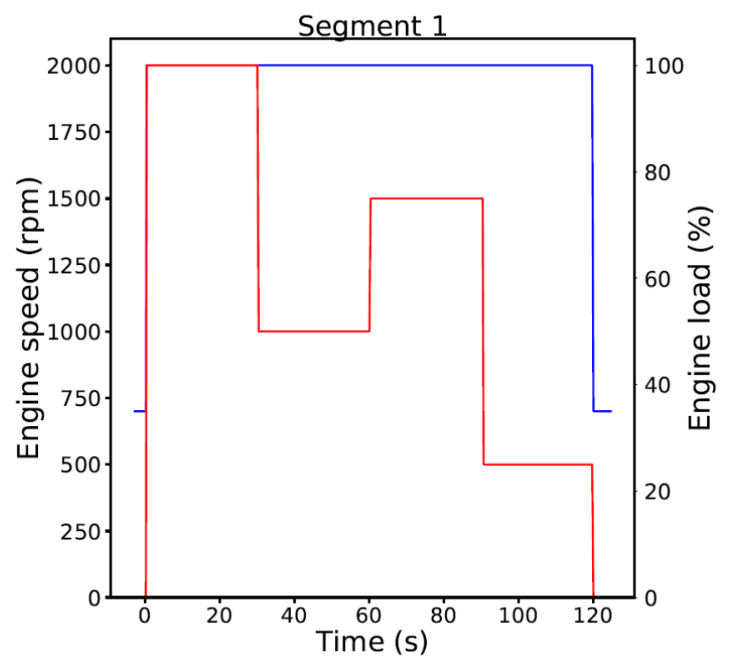

(b) $2000 \mathrm{rpm}$

Figure 1. Engine speed and load changes during one (of eight) engine run segments of the custom designed drive cycle at (a) $1500 \mathrm{rpm}$ and (b) $2000 \mathrm{rpm}$. The blue line corresponds to the engine speed and the red line corresponds to the engine load.

\subsection{Experimental Methodology}

The investigation in the current study was based on discretising the engine warm up into different stages to analyse the influence of these engine warm up on combustion. The classification of the engine warm up stages has been based on coolant and oil temperatures, and this classification has been discussed in detail in the previous study by the authors [20]. However, they are briefly mentioned here for clarity. Stage 1 is referred to as the cold start stage, in which the engine coolant temperature is $<70{ }^{\circ} \mathrm{C}$; Stage 2 is referred to as the intermediate cold start stage because the engine coolant temperature is between $70{ }^{\circ} \mathrm{C}$ and $90^{\circ} \mathrm{C}$, while the oil temperature is $<70{ }^{\circ} \mathrm{C}$; Stage 3 is referred to as the warm start stage because the engine coolant temperature is $>90^{\circ} \mathrm{C}$ and the oil temperature is between $70{ }^{\circ} \mathrm{C}$ and $90^{\circ} \mathrm{C}$; and Stage 4 is referred to as the hot start stage as the both the engine coolant and oil are $>90^{\circ} \mathrm{C}$ with the engine completely warmed up.

\section{Results and Discussion}

In the current study, mean values of the combustion parameters were calculated to analyse the results. When calculating the mean, approximately $5 \mathrm{~s}$ of the data at the start of each load in each segment was excluded because of the highly transient nature of the experimental data, which was caused by the turbocharger lag [21]. In the subsequent section, the influence of different stages of engine warm up on different combustion parameters such as the MFB, start of injection (SOI), SOC, ignition delay, combustion duration, end of combustion (EOC), CA duration of 50\% MFB (CA50), apparent heat release rate at CA50 (AHRR @ CA50) and CA duration of 10 to 90\% MFB (CA10-90) were analysed.

During the experiments, it was observed that a restriction to achieve maximum load was applied by the ECU in Segments 1 and 2 at $1500 \mathrm{rpm}$. The restriction was likely used as a safety measure to protect the engine from any potential failure, since $1500 \mathrm{rpm}$ was the engine speed for rated torque. The maximum load restrictions were not applied at $2000 \mathrm{rpm}$. It was also observed that the ECU 
followed an advanced injection strategy during Stage 1 (Segments 1 and 2), while at the end of Segment 2 , the ECU switched to a retarded injection strategy. An advanced injection strategy during Stage 1 was used to achieve higher peak in-cylinder temperature and pressure to facilitate faster warm up of the engine, while a retarded injection strategy assisted in lowering the peak in-cylinder temperature and pressure (with a benefit to reduce NOx emissions).

\subsection{Combustion Analysis}

Diesel engine combustion involves fairly complex physical and chemical processes with high nonuniformity [4]. However, before the fuel is burnt in the cylinder, spray penetration of the liquid fuel in the compressed air and atomisation of the liquid droplets must be established [4]. The speed and extent to which the fuel spray travels across the combustion chamber affects the air utilisation and mixture preparedness rates [2]. Moreover, as the liquid fuel enters the combustion chamber, the temperature of the droplets increases due to heat transfer. The fuel vapour pressure also increases, eventually increasing the evaporation rate [2]. Finally, as the fuel vaporises, the air temperature decreases and the local fuel pressure increases, leading to thermodynamic equilibrium [2].

The cylinder pressure versus the CA data of the engine operating cycle can be used to obtain quantitative information about the combustion process [2,7]. The HRR is calculated from the first law of thermodynamics, shown in Equation (1), using the cylinder pressure data.

$$
\frac{d Q}{d t}-p \frac{d V}{d t}+\sum_{i} \dot{m}_{i} h_{i}=\frac{d U}{d t}
$$

where $\frac{d Q}{d t}$ is the rate of heat transfer across the system boundary into the system, $p \frac{d V}{d t}$ is the rate of work transfer done by the system due to system boundary displacement, $\dot{m}_{i}$ is the mass flow rate across the system boundary at location $i, h_{i}$ is the enthalpy of flux $i$, entering or leaving the system and $U$ is the energy of the material contained inside the system boundary [2].

In the current study, experimentally measured in-cylinder pressure were used to calculate the HRR and to conduct the combustion analysis, which is a subject of discussion in the subsequent subsections. The aim of the combustion analysis in the current study was to understand the influence of engine warm up on in-cylinder combustion.

\subsection{COV of the IMEP}

When the injection timing is advanced, the cycle to cycle variations increase and it becomes difficult to obtain repeatable combustion [2]. Since the mixing of the fuel is controlled by the in-cylinder flow dynamics, which is complicated and highly turbulent particularly during the cold start period, it may consequently lead to misfires and/or partial burning in some cycles [5]. As a result, there could be some cycles with sporadic, short and rapid spikes in the heat release, while other cycles are low, causing significant cyclic variations during cold start [22]. The coefficient of variation (COV) of the indicated mean effective pressure (IMEP) is a parameter commonly used as a measure of combustion stability [2,4,7]. It gives a quantitative estimate of the combustion instability and cyclic variability [22]. As reported by Heywood [2], vehicle drivability problems usually occur when the COV of the IMEP exceeds $10 \%$. The COV of the IMEP is defined as

$$
\mathrm{COV} \text { of the IMEP }=\left(S T D_{I M E P} / M E A N_{I M E P}\right) \times 100
$$

where $S T D_{I M E P}$ is the standard deviation of the IMEP and $M E A N_{I M E P}$ is the arithmetic mean of the IMEP [2].

The relatively low values of the COV of the IMEP found at each load in each segment indicate that the cyclic variations settled down within a few seconds after a change of load, since the first $5 \mathrm{~s}$ of highly transient data was excluded in each load, as shown in Figure 2a,b. The COV of the IMEP was 
found to range between $0.3 \%$ to $0.7 \%$, at $100 \%, 75 \%$ and $50 \%$ loads, while at $25 \%$ load, it was been observed to range between $1.0 \%$ to $1.4 \%$. Usually, the cyclic variations increase with the introduction of any combustion phenomenon that slows down the combustion process, such a: lean mixture operation, exhaust gas residuals and low load operation [7].

$>100 \%$ load $>50 \%$ load $\quad$ - $75 \%$ load $25 \%$ load

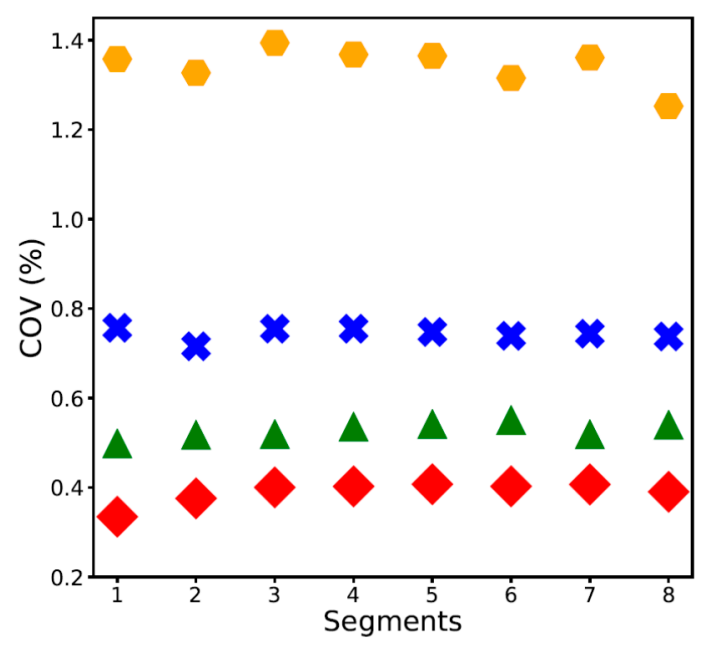

(a) $1500 \mathrm{rpm}$

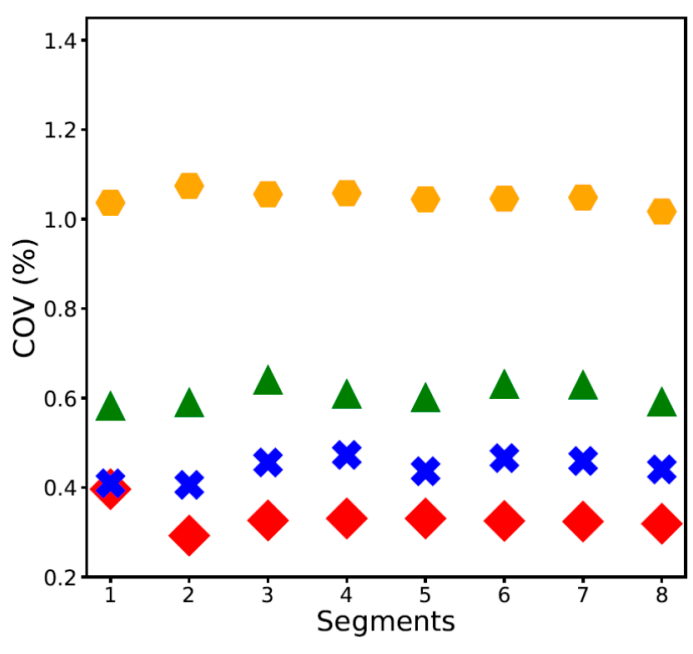

(b) $2000 \mathrm{rpm}$

Figure 2. COV of IMEP at all loads in each stage at (a) $1500 \mathrm{rpm}$ and (b) $2000 \mathrm{rpm}$. The red thick diamond represents $100 \%$ load, the blue thick cross $50 \%$ load, the green triangle $75 \%$ load and the orange hexagon $25 \%$ load.

During Stage 1 (cold start), the COV of the IMEP were lower in Segment 2 when compared to Segment 1 , which was associated with engine coolant temperature increase from approximately $25^{\circ} \mathrm{C}$ to $45{ }^{\circ} \mathrm{C}$ in Segment 1 and approximately $50{ }^{\circ} \mathrm{C}$ to $60{ }^{\circ} \mathrm{C}$ in Segment 2 . However, at $100 \%$ load at $1500 \mathrm{rpm}$, the COV of the IMEP was observed to increase in Segment 2, which can be explained by the engine restrictions applied. The higher COV of the IMEP during Segment 1 was most likely due to the cold cylinder walls hindering fuel atomisation and causing higher combustion instability.

During Stage 2 (intermediate cold start-), the COV of the IMEP increased by approximately $5 \%$ to $6 \%$ and $8 \%$ to $11 \%$ at $1500 \mathrm{rpm}$ and $2000 \mathrm{rpm}$, respectively, as compared to Stage 1 . As the engine coolant temperature reached $70{ }^{\circ} \mathrm{C}$ in Segment 3, the injection strategy switched to a retarded injection to decrease the in-cylinder pressure and temperature. The rise in engine coolant temperature could have caused a decrease, while at the same time, the retarded injection could have caused an increase in combustion instability. The effect of retarded injection seemed to have dominated over the coolant temperature, thus causing an increase in the combustion instability and a subsequent increase in the COV of the IMEP in Segment 3.

During Stage 3 (warm start), the COV of the IMEP varied between $\pm 2 \%$, comparing Segments 4 and 5 . However, it was interesting to see a higher variation between Stages 2 and 3 (varying between $-5 \%$ to $+4 \%$.) A higher discrepancy here is indicative of the effects of suboptimum oil temperature. In this stage, the coolant temperature was greater than $90^{\circ} \mathrm{C}$, while the oil temperature was between $70{ }^{\circ} \mathrm{C}$ and $90^{\circ} \mathrm{C}$. Therefore, the engine was still not completely stabilised.

During Stage 4 (hot start), the COV of the IMEP decreased by approximately $2 \%$ to $5 \%$, from Segments 6 to 8 , as the engine became warmed up and stabilised, whereas, from Stages 3 to 4 (from Segments 5 to 8 ), it decreased by approximately $2 \%$ to $9 \%$. It is observed that the COV of the IMEP decreased by approximately $4 \%$ to $12 \%$, when Stages 1 and 4 were compared. This is 
indicative that the cyclic variations decreased as the engine reached stability, with the coolant and oil temperatures both becoming greater than $90^{\circ} \mathrm{C}$ and all of the engine components warmed up.

The COV was observed to be approximately higher by $10 \%$ to $40 \%$ at $1500 \mathrm{rpm}$ compared with $2000 \mathrm{rpm}$ when each load was compared, which could have been due to smoother combustion at $2000 \mathrm{rpm}$.

\subsection{In-Cylinder Pressure Data}

The experimental raw pressure data was smoothed to remove noise. Smoothing was done by discretising the cycle data into overlapping windows and fitting a higher order polynomial in each window. This is a commonly used technique, as it ensures that the features of the cycle are maintained and only the noise is removed [23-25]. Figure 3a-d show the comparison between the in-cylinder pressure, at each load in each segment, at $1500 \mathrm{rpm}$. Similar trends in the in-cylinder pressure trace were evident at $2000 \mathrm{rpm}$. However, they are not included here. The in-cylinder pressure analysis during the various stages of engine warm up is presented in this section.

During Stage 1 (cold start), in Segments 1 and 2, higher in-cylinder pressure were observed. The effects of lower in-cylinder temperature in Stage 1, due to the cold start, resulted in a lag and lower pressure rise during the compression stroke, which can be observed in Figure 3a-d when compared with Stages 2, 3 and 4 . These effects seems to be more prominent at higher loads ( $100 \%$ and $75 \%$ loads). The higher peak in-cylinder pressure were most likely due to an advanced injection strategy followed by the engine during this stage. Moreover, the peak pressure at each load in Segment 2 were observed to be approximately $2 \%$ to $4 \%$ higher than Segment 1 , owing to the combined effect of the advanced injection strategy and rise in in-cylinder temperature, as the engine coolant temperature was increased from $50{ }^{\circ} \mathrm{C}$ to $60^{\circ} \mathrm{C}$ in Segment 2 and from $25^{\circ} \mathrm{C}$ to $45^{\circ} \mathrm{C}$ in Segment 1.

Injection timing has a significant influence on the in-cylinder environment. Advancing the injection timing to have the combustion occur earlier in the cycle increases the peak cylinder pressure, as more fuel is burnt in the premixed combustion stage either before or close to top dead centre (TDC), where the cylinder volume is minimum $[2,4,7]$. Higher peak pressure results in a higher peak temperature $[2,4,7]$, consequently supporting a faster engine warm up, which was required in Stage 1 . Since the combustion phenomenon finishes earlier, it not only leads to higher in-cylinder temperature and pressure, but also provides more time for the gases to expand in the expansion stroke. Similarly, retarding the injection decreases the peak cylinder pressure, as more fuel is burnt in the diffusion stage later in the expansion stroke $[2,4,7]$. The engine switched to a retarded injection strategy when the engine reached an intermediate temperature of $65^{\circ} \mathrm{C}$ at the end of Segment 2.

During Stage 2 (intermediate cold start), it was observed that the in-cylinder pressure decreased when compared to cold start (Stage 1), due to the retarded injection strategy in Segment 3. It can be further observed in Stage 2 that peak pressure occurred close to TDC, while the SOC occurred late in the expansion stroke, leading to an insignificant pressure rise due to combustion, thereby decreasing the heat release and lowering the in-cylinder temperature during combustion. This was due to the SOI at all loads in Stage 1 (Segments 1 and 2) occurring before TDC, while in Stage 2, with the retarded injection strategy, the SOI was observed to occur after TDC. Therefore, the initiation of combustion late in the expansion stroke could have led to most of the burning taking place in the diffusion combustion stage without causing a significant increase in the temperature or pressure, as an increase in volume was occurring at the same time. Therefore, the peak pressure dropped significantly, by approximately $25 \%$ in Stage 2 compared to Stage 1 , when the coolant temperature was greater than $70{ }^{\circ} \mathrm{C}$ with retarded injection, while the oil temperature was less than $70^{\circ} \mathrm{C}$.

During Stage 3 (warm start), the in-cylinder pressure increased by approximately $1 \%$ to $2 \%$, compared to Stage 2, as the coolant temperature reached greater than $90{ }^{\circ} \mathrm{C}$, while the oil temperature was between $70^{\circ} \mathrm{C}$ and $90^{\circ} \mathrm{C}$. During Stage 3, the in-cylinder pressure varied between $\pm 0.3 \%$ between Segments 4 and 5. During Stage 4 (hot start), the in-cylinder pressure remained consistent within a 
variation of approximately $\pm 0.5 \%$ in Segments 6,7 and 8 , as the coolant and oil temperatures were greater than $90^{\circ} \mathrm{C}$ in this stage and the engine was thermally stable.

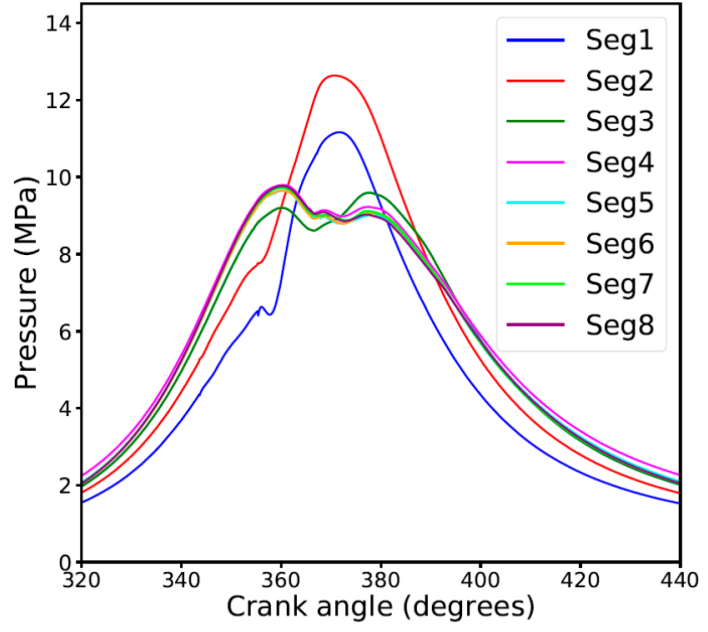

(a) $100 \%$ load

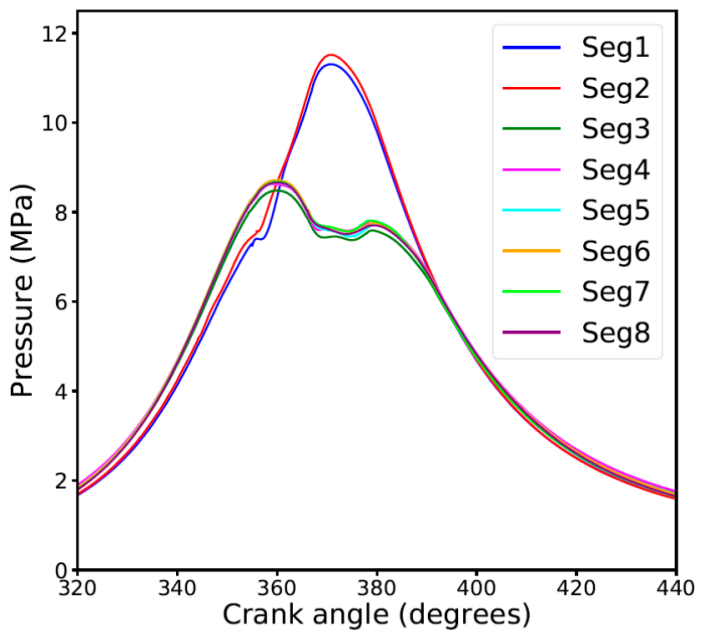

(c) $75 \%$ load

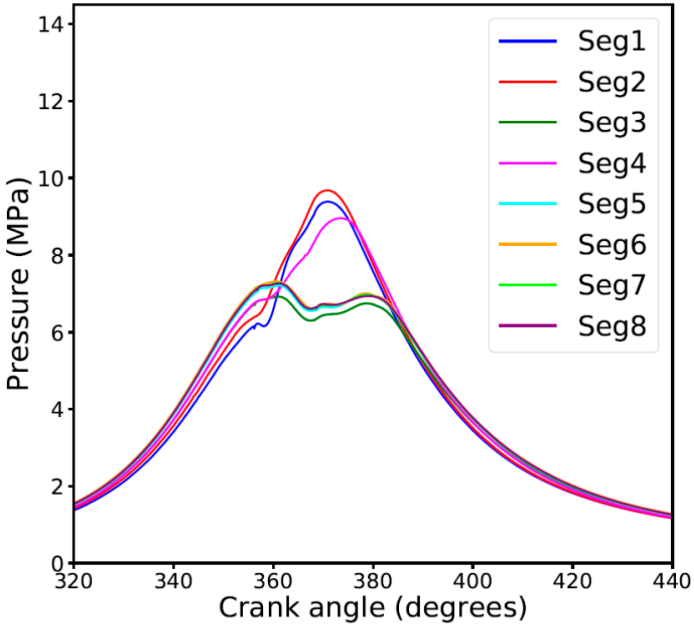

(b) $50 \%$ load

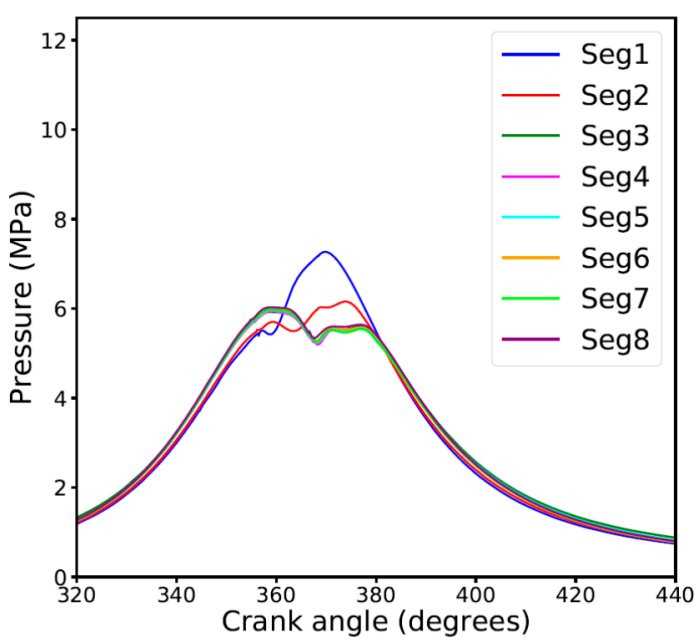

(d) $25 \%$ load

Figure 3. In-cylinder pressure in each segment at $1500 \mathrm{rpm}$ at (a) $100 \%$ load, (b) $50 \%$ load, (c) $75 \%$ load and (d) 25\% load. The blue line represents Segment 1, red line represents Segment 2, green line represents Segment 3, magenta line represents Segment 4, cyan line represents Segment 5, orange line represents Segment 6, lime line represents Segment 7 and purple line represents Segment 8.

A systematic rise in peak pressure was observed through Stages 1,2 and 3, when the engine was warming up. However, the pressure rise levelled out in Stage 4, when the engine had fully warmed up. This could have been due to the initiation temperature in a cycle being high in the warmed-up stage, which could significantly impact the in-cylinder temperature later during the cycle, given the polytropic compression process. 


\subsection{Mass Fraction Burned}

In the current study, the MFB was calculated using the single Wiebe function [2], given in Equation (3). The use of a single and double Weibe function to predict the combustion MFB has been discussed by the authors of $[9,10]$. The Weibe function is a simple yet powerful correlation to predict the MFB in an internal combustion engine (ICE) [2]. The solution of Equation (3) produces an S-shaped curve, commonly used to characterise the mass fraction burned $[2,10]$. The S-shaped Wiebe profile tends to exponentially increase from zero to a value close to 1 (where the zero mass fraction burned indicate the SOC and 1 is indicative of the EOC). The difference between the SOC and EOC is the combustion duration $[2,10]$.

$$
x_{b}=1-\exp \left[-a\left(\frac{\theta-\theta_{0}}{\Delta \theta}\right)^{m+1}\right]
$$

where $x_{b}$ is the mass fraction burned, $\theta$ is the crank angle, $\theta_{0}$ is the SOC, $\Delta \theta$ is the combustion duration, $m$ is called the shape or form factor (because it determines the shape of the combustion process) and $a$ is called the efficiency parameter (because it controls the duration of the combustion process) $[7,9,10,12]$. The integral of $x_{b}(\theta)$ over the whole combustion duration $\Delta \theta$ is close to but never equal to 1 . A value of 1 would only be possible if the value of $a$ was equal to infinity [9].

In the current study, the values of $m$ and $a$ were selected to be 6.9 and 1, respectively, referring to the literature $[9,10,12]$. The values of $m$ and $a$ used in the current study were also validated on a combustion model, developed for the same engine as used in experiments in a previous study conducted by Lodi et al. [26]. The nominal injection information was obtained by analysing the injector information sent by the ECU. The engine in the current study used a single injection for all of the operating conditions under investigation. The SOC in the current study was determined using the method introduced by Bodisco et al. [27]. This method identifies the start of combustion by analysing a band-passed (4-20 kHz) in-cylinder pressure signal for the start of a strongly periodic feature (at $\sim 6 \mathrm{kHz}$ ). This strong periodicity is a consequence of acoustic resonance associated with combustion and is commonly referred to as combustion resonance [27,28]. After fuel injection has taken place, heat is transferred from the air to the liquid fuel spray as sensible heat and latent heat of evaporation and the energy of the endothermic reactions in the fuel prior to combustion [6,29]. There is also an influence from the heat losses from the gas to the wall in this phenomenon [29]. Initially, at the start of combustion, the heat released does not immediately match this phenomenon, influencing the negative heat transfer. Therefore, the method by Bodisco et al. [27] corresponds to the point at which the gradient of the HRR curve becomes positive, rather than the HRR becoming positive, and is thus considered to be more accurate than the traditional means of determining the SOC $[2,7,11]$. The EOC in the current study was estimated using the method by Mendera et al. [30]. It was calculated as the CA where the minimum value of the derivative of the product of $p V$ occurs ( $p$ is the in-cylinder pressure and $V$ is the volume), corresponding to the minimal value of the sensible internal energy change. Figure 4 shows the SOC, EOC and combustion duration in the current study on an AHRR diagram.

\subsection{Apparent Heat Release Rate (AHRR)}

The heat release in diesel combustion takes place in two stages: The first being the premixed combustion phase (where the fuel which is already mixed, burns), and the second being the mixing controlled combustion phase. Although the rates of burning in the second phase are lower, the majority of the fuel is burnt in this stage [2]. Longer ignition delays allow more time for the fuel to mix within the combustible limits. Therefore, the AHRR increases in the premixed combustion phase [2]. The influence of the engine coolant and oil temperature in the different stages of engine warm up on the AHRR have been presented in this section. Figures $5-8$ show the AHRR at $100 \%, 50 \%, 75 \%$ and $25 \%$ load, at $1500 \mathrm{rpm}$ and $2000 \mathrm{rpm}$. 


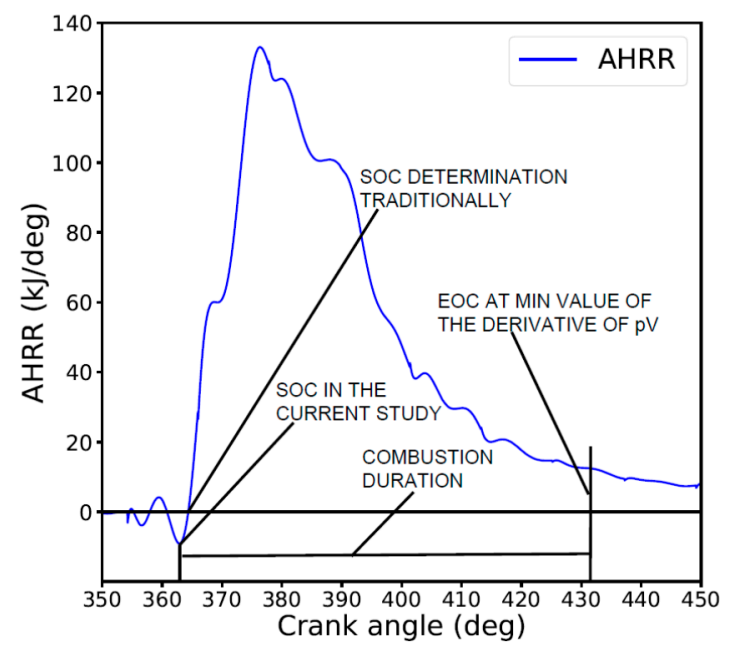

Figure 4. AHRR diagram showing SOC, EOC and combustion duration (50th cycle) at 100\% load in Segment 8 of Stage 4 at $2000 \mathrm{rpm}$.

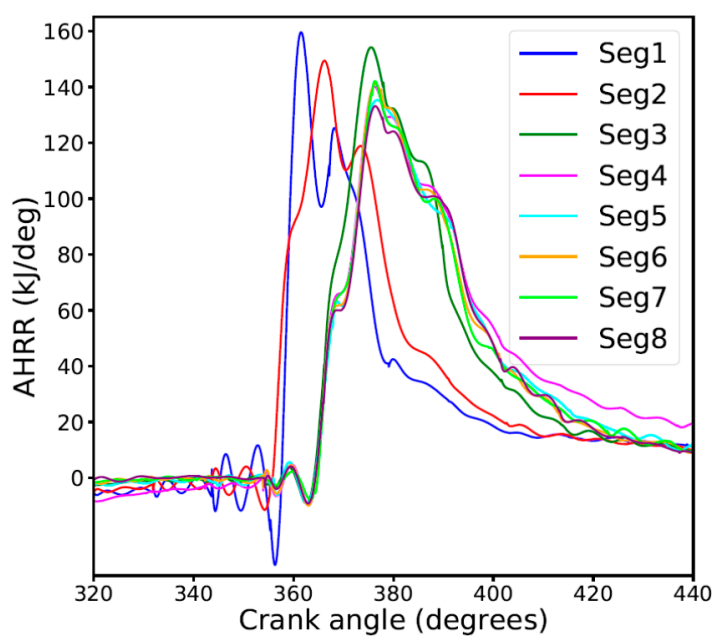

(a) $1500 \mathrm{rpm}$

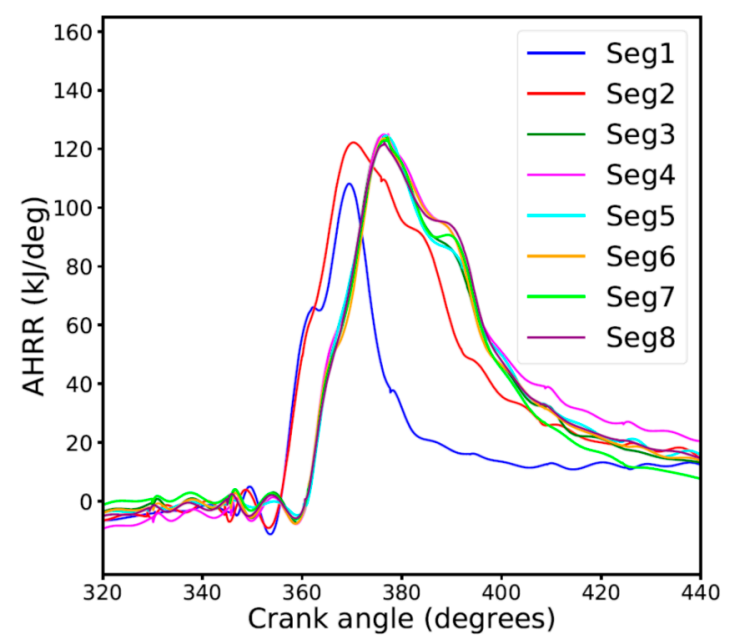

(b) $2000 \mathrm{rpm}$

Figure 5. Apparent Heat Release Rate (AHRR) at 100\% load in each segment in all stages at (a) $1500 \mathrm{rpm}$ and (b) $2000 \mathrm{rpm}$. The blue line represents Segment 1, red line represents Segment 2, green line represents Segment 3, magenta line represents Segment 4, cyan line represents Segment 5, orange line represents Segment 6, lime line represents Segment 7 and purple line represents Segment 8.

During Stage 1, the peak AHRR was observed to occur earlier compared to the Stages 2, 3 and 4 . Moreover, higher values of peak AHRR were also observed in Stage 1. This could have been due to the advanced injection strategy used by the engine in Stage 1 [2]. Furthermore, the peak AHRR increased by approximately $2 \%$ in Segment 2 compared to Segment 1, which was likely due to the increase in the engine coolant temperature from $25^{\circ} \mathrm{C}$ to $45^{\circ} \mathrm{C}$ in Segment 1 to $50{ }^{\circ} \mathrm{C}$ to $60^{\circ} \mathrm{C}$ in Segment 2 .

The shape of the AHRR curve in Stage 1 showed a steep and rapid rise, while in Stages 2, 3 and 4, it appeared to be more spread out. The most likely reason for this was the advanced injection of the fuel before TDC, toward the end of the compression stroke, resulting in a longer ignition delay. In this stage, it is likely that most of the fuel was burned in the premixed combustion stage, leading to a rapid rise in the pressure and AHRR with a shorter combustion duration. 


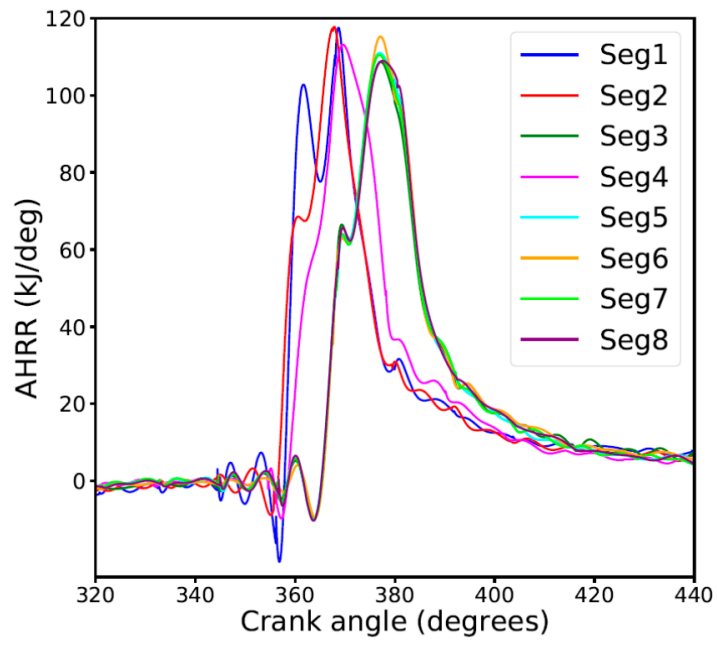

(a) $1500 \mathrm{rpm}$

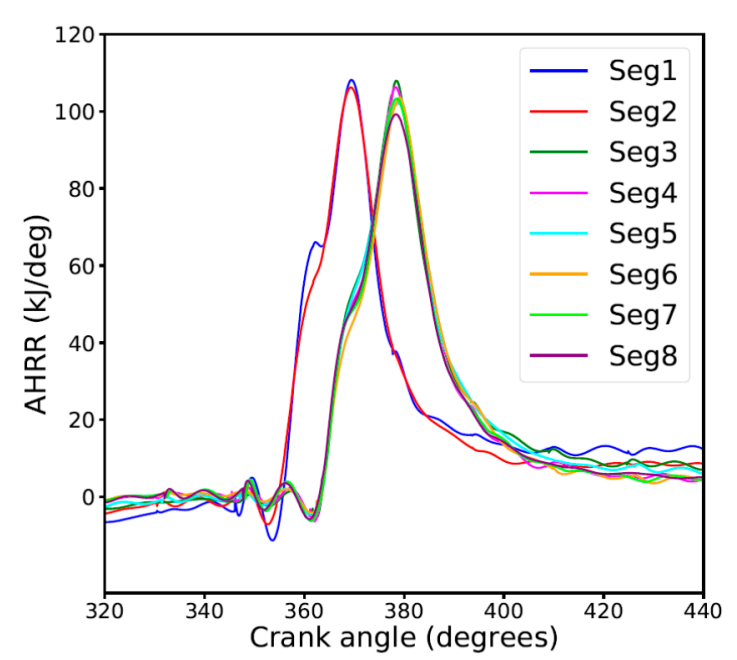

(b) $2000 \mathrm{rpm}$

Figure 6. AHRR at 50\% load in each segment in all stages at (a) $1500 \mathrm{rpm}$ and (b) $2000 \mathrm{rpm}$. The blue line represents Segment 1, red line represents Segment 2, green line represents Segment 3, magenta line represents Segment 4, cyan line represents Segment 5, orange line represents Segment 6, lime line represents Segment 7 and purple line represents Segment 8.

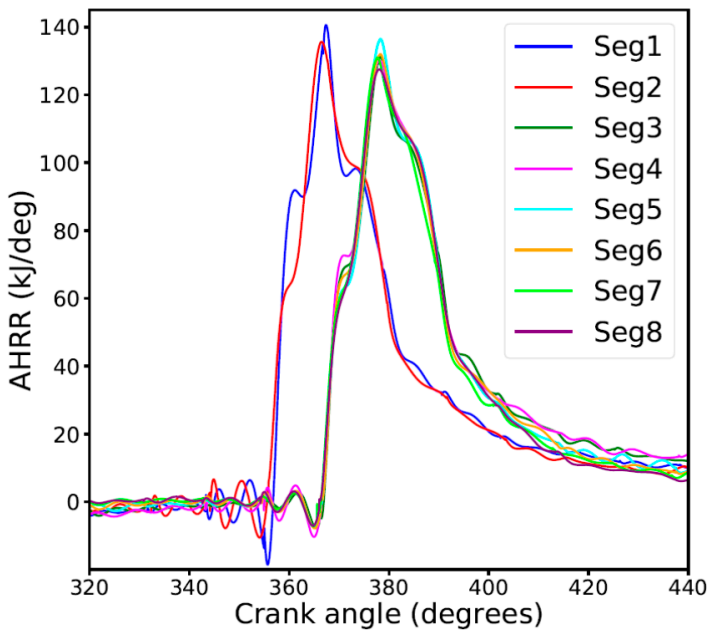

(a) $1500 \mathrm{rpm}$

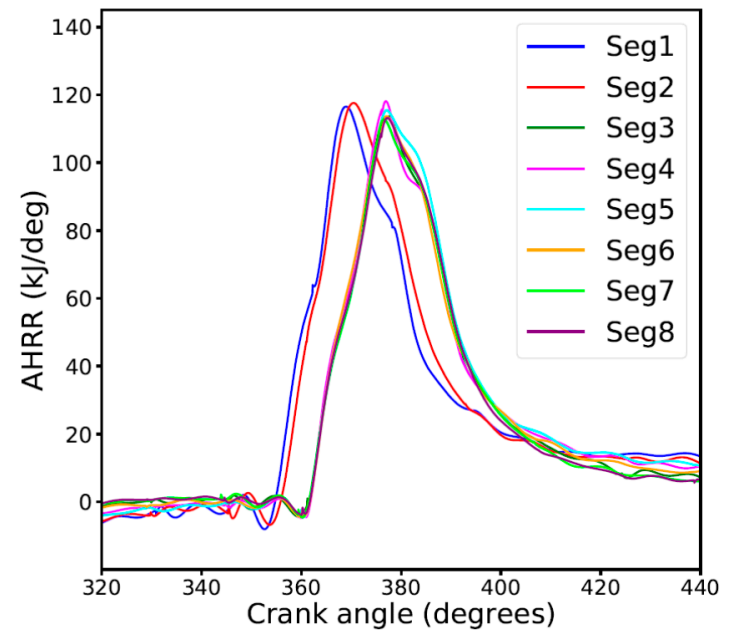

(b) $2000 \mathrm{rpm}$

Figure 7. AHRR at 75\% load in each segment in all stages at (a) $1500 \mathrm{rpm}$ and (b) $2000 \mathrm{rpm}$. The blue line represents Segment 1, red line represents Segment 2, green line represents Segment 3, magenta line represents Segment 4, cyan line represents Segment 5, orange line represents Segment 6, lime line represents Segment 7 and purple line represents Segment 8.

During Stage 2, a decrease in the AHRR of approximately 1\% to 4\% was observed, which could have been due to injection strategy change in Segment 3. As the injection was retarded in Segment 3, shorter ignition delays with longer combustion durations were observed. This is attributed to more fuel being burnt late in the diffusion stage, leading to lower peak pressure and peak AHRR [2]. Although the coolant temperature in this stage was greater than $70^{\circ} \mathrm{C}$, the oil temperature was less than $70{ }^{\circ} \mathrm{C}$. Therefore, it seems that the effects of the injection strategy dominated over the engine warm up in this stage and led to a decrease in the AHRR. 


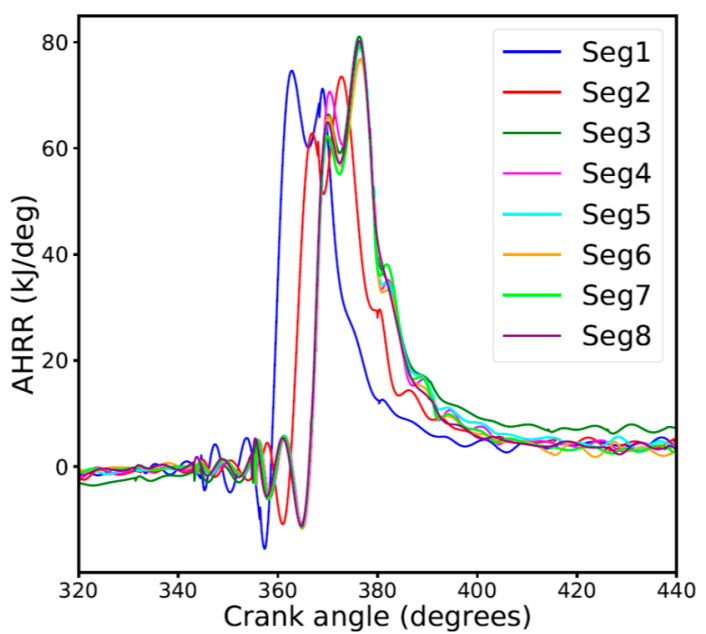

(a) $1500 \mathrm{rpm}$

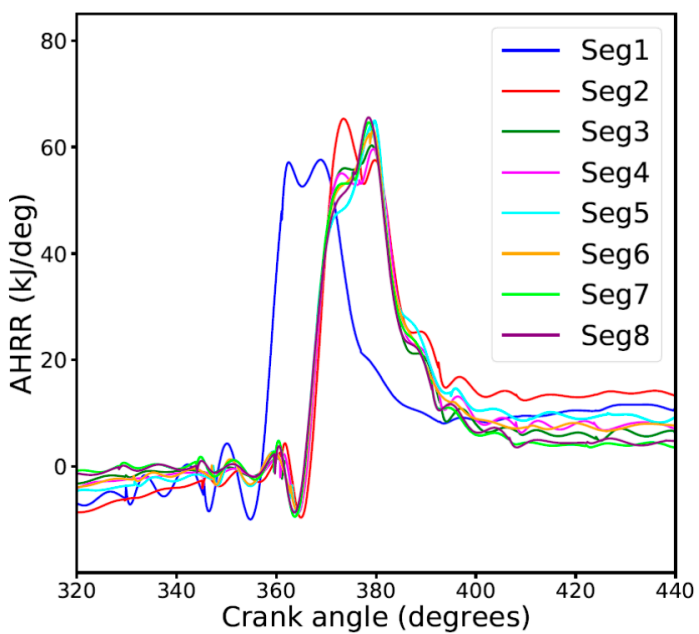

(b) $2000 \mathrm{rpm}$

Figure 8. AHRR at $25 \%$ load in each segment in all stages at (a) $1500 \mathrm{rpm}$ and (b) $2000 \mathrm{rpm}$. The blue line represents Segment 1, red line represents Segment 2, green line represents Segment 3, magenta line represents Segment 4, cyan line represents Segment 5, orange line represents Segment 6, lime line represents Segment 7 and purple line represents Segment 8.

During Stage 3, an increase in the peak AHRR by approximately $0.5 \%$ to $2 \%$ was observed when compared to Stage 2. The increase in the AHRR in this stage could be indicative of the influence of oil warm up, as the oil reached $90^{\circ} \mathrm{C}$ during this stage, while the injection strategy remained consistent as it was in Stage 2. Moreover, during Stage 4, the AHRR approximately varied between \pm 0.5 to $\pm 1 \%$ from Segments 5 and onward, as the engine achieved stability in this stage, with both the coolant and oil temperatures reaching greater than $90^{\circ} \mathrm{C}$.

\subsection{Combustion Parameters}

Combustion phasing greatly influences the engine performance and emissions [9]. During the combustion process, a 10\% mass fraction burned (MFB10) is mainly associated with early flame development, a 50\% mass fraction burned (MFB50) is correlated with efficiency and emissions, while a $90 \%$ mass fraction burned (MFB90) is associated with the end of bulk burning [2,9]. In the current study, the mass fraction burned was calculated for each cycle, at each load in each segment, at both engine speeds, $1500 \mathrm{rpm}$ and $2000 \mathrm{rpm}$, using a single zone heat release model in Equation (3), as discussed in Section 3.4 [2]. The combustion behaviour was further analysed by calculating the CA duration at MFB50, called CA50; AHRR at CA50, called AHRR@CA50; and CA duration between MFB10 and MFB90, called CA10-90. These combustion parameters were calculated for all cycles. However, due to a large number of cyclic variations observed in the combustion data, especially during Stage 1 (Segments 1 and 2), some cycles which showed as complete outliers in the data were removed from the analysis. Thus, the mean values of the remaining cycles at each load in each segment, showed a more meaningful representation of the results. The combustion parameters included in the analysis are the SOI, SOC, ignition delay, EOC, combustion duration, CA50, AHRR@CA50 and CA10-90.

\subsubsection{The SOI, SOC, Ignition Delay and EOC}

During Stage 1, it was observed that the advanced injection strategy used in Segments 1 and 2 was also complimented with a late SOC, thus increasing the ignition delay. Figures 9-12 show the SOI, SOC, ignition delay and EOC at each load in the different stages of the custom cycle at 1500 and $2000 \mathrm{rpm}$. A longer ignition delay, as observed during Stage 1, could have aided mixture uniformity [12,22]. It has been reported by Aklouche et al. [31] that a longer ignition delay leads to an 
accumulation of fuel, which burns at a faster rate during the premixed combustion stage, leading to a rapid rise in the peak pressure and AHRR values. Moreover, pilot injections are included in modern common rail turbocharged engines with advanced timing, which help to create additional ignition centres in the cylinder, consequently adding to more uniformity in the mixture [22]. Although the SOC of these distributed ignition centres, created through pilot injections, start early in the compression stroke, the bulk of the fuel initially remains unburnt and therefore has sufficient time to mix uniformly. The initial burning of the pilot injection ignition centres helps to increase the rate of pressure rise, consequently leading to higher in-cylinder pressure and temperature during cold start [22], as also observed through higher peak pressure and peak AHRR in the current study. The EOC has been observed to occur early in Stage 1, which is indicative of a rapid combustion taking place, most likely in the premixed combustion phase, leading to higher peak in-cylinder pressure and peak AHRR.

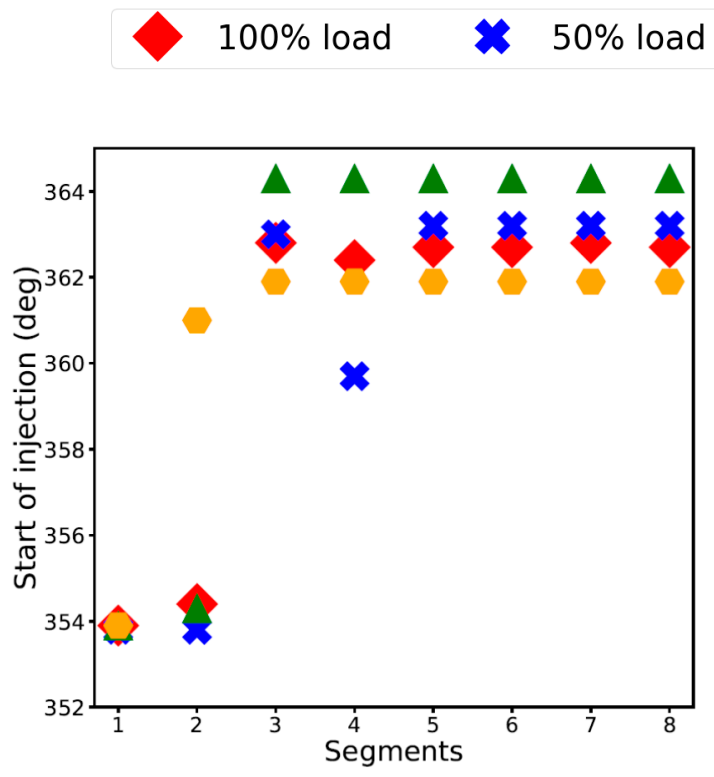

(a) $1500 \mathrm{rpm}$
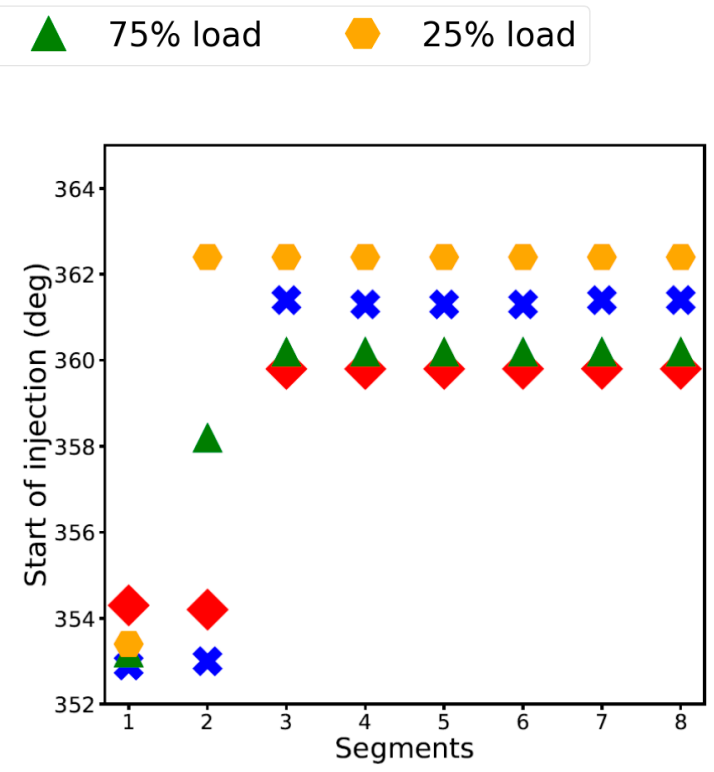

(b) $2000 \mathrm{rpm}$

Figure 9. Start of injection at all loads in each stage at (a) $1500 \mathrm{rpm}$ and (b) $2000 \mathrm{rpm}$. The red thick diamond represents $100 \%$ load, the blue thick cross $50 \%$ load, the green triangle $75 \%$ load and the orange hexagon $25 \%$ load (Figure adapted from [20]).

In a compression ignition $(\mathrm{CI})$ engine, when the piston moves up in the compression stroke, the in-cylinder pressure and temperature increase. If the injection timing is advanced, it may lead to misfire or partial combustion during cold start, since the local temperature and pressure are not sufficient to support instantaneous ignition [2]. In the current study, higher cyclic variations were observed during Stage 1. Moreover, comparatively higher ignition delays and shorter combustion durations were observed at each load at $1500 \mathrm{rpm}$ compared to $2000 \mathrm{rpm}$. This ensured a more rapid combustion at $1500 \mathrm{rpm}$, resulting in higher peak pressure compared to $2000 \mathrm{rpm}$, since $1500 \mathrm{rpm}$ was the engine speed for rated torque for the experimental engine under study. Nevertheless, in the current study, the advanced injection strategy during the cold start of the engine was successful in producing higher in-cylinder peak pressure and temperature and consequently leading to a faster engine warm up.

During Stage 2, it was observed that the engine switched to a retarded injection strategy in Segment 3. In this stage, the SOI was observed to occur after the TDC in the expansion stroke, with decreased ignition delay and longer combustion duration, thus resulting in a lowering of the in-cylinder pressure and temperature. During Stages 3 and 4, the SOI, SOC, ignition delay and EOC remained consistent, and no further changes were observed when compared to Stage 2. 


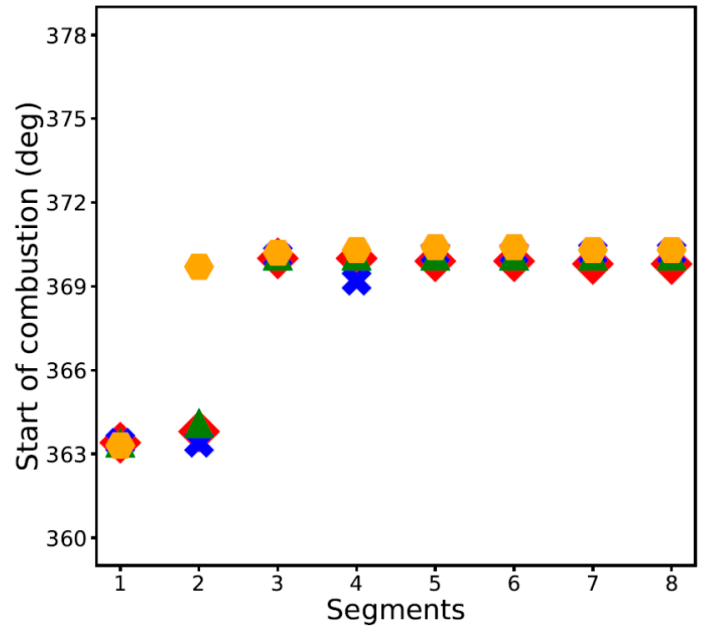

(a) $1500 \mathrm{rpm}$

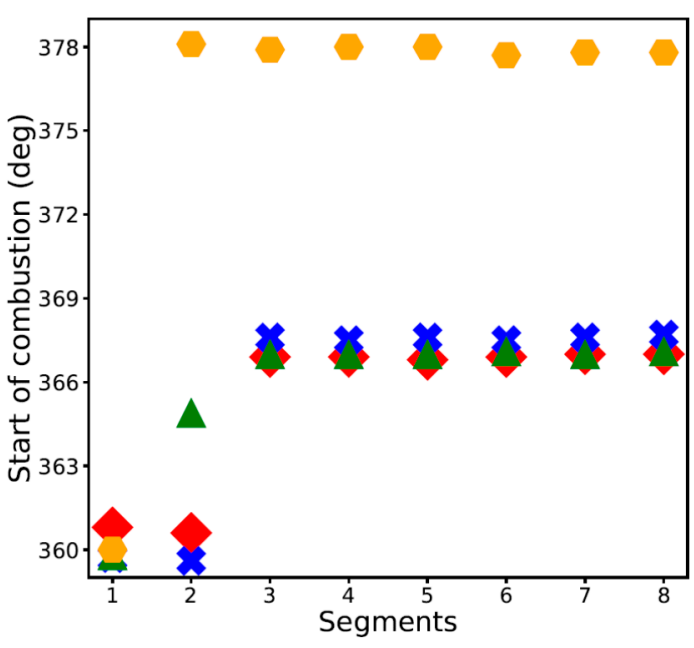

(b) $2000 \mathrm{rpm}$

Figure 10. Start of combustion at all loads in each stage at (a) $1500 \mathrm{rpm}$ and (b) $2000 \mathrm{rpm}$. The red thick diamond represents $100 \%$ load, the blue thick cross $50 \%$ load, the green triangle $75 \%$ load and the orange hexagon $25 \%$ load.

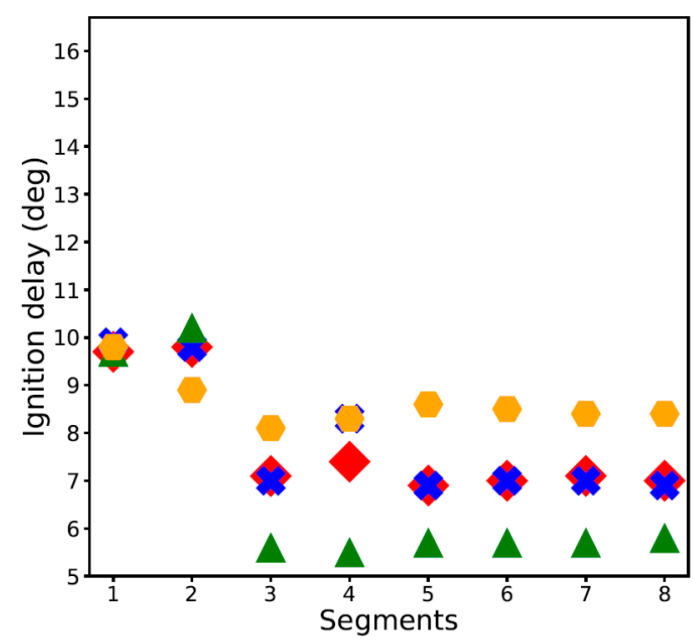

(a) $1500 \mathrm{rpm}$

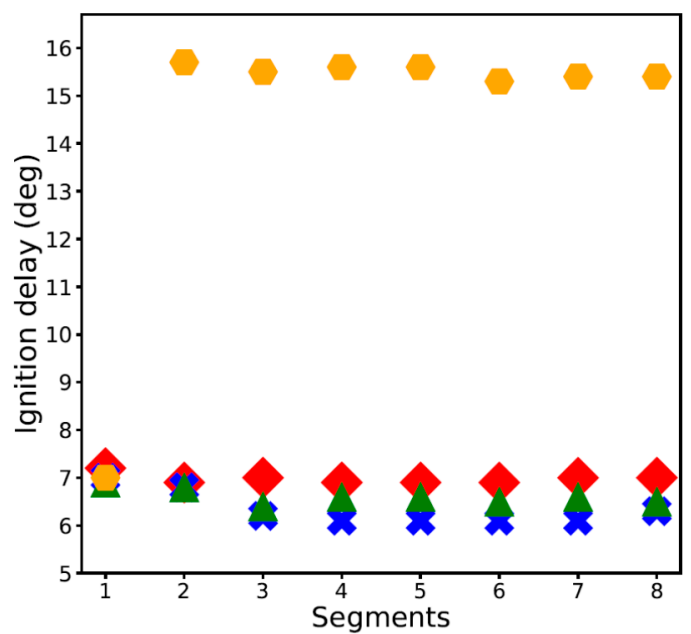

(b) $2000 \mathrm{rpm}$

Figure 11. Ignition delay at all loads in each stage at (a) $1500 \mathrm{rpm}$ and (b) $2000 \mathrm{rpm}$. The red thick diamond represents $100 \%$ load, the blue thick cross $50 \%$ load, the green triangle $75 \%$ load and the orange hexagon $25 \%$ load.

With the injection retarded in Stage 2 and the ignition delay shortened at all of the engine loads, an exceptional behaviour was observed in the case of 25\% load at $2000 \mathrm{rpm}$ in Stage 2 and onward, where the ignition delay period was observed to increase by approximately $7{ }^{\circ} \mathrm{CA}$. Moreover, the combustion duration also decreased at 25\% load in Stage 2 by approximately 25\%, as compared to Stage 1 (comparing Segments 1 and 3) at $2000 \mathrm{rpm}$, and stayed consistent thereafter in later stages. The most likely reason for a longer ignition delay was to allow for more mixture uniformity at this load and to combust the fuel rapidly in a shorter combustion duration producing higher in-cylinder pressure, since $2000 \mathrm{rpm}$ was the engine speed for rated power in the experimental engine under study. Although, as compared to Stage 1 at $2000 \mathrm{rpm}$ a shorter combustion duration at 25\% load in Stage 2 and onward could have contributed to producing higher torque and power by producing 
higher in-cylinder pressure, the increased ignition delay can result in the deterioration of combustion, producing higher HC emissions [2]. This has also been shown in the previous study by the author [20].

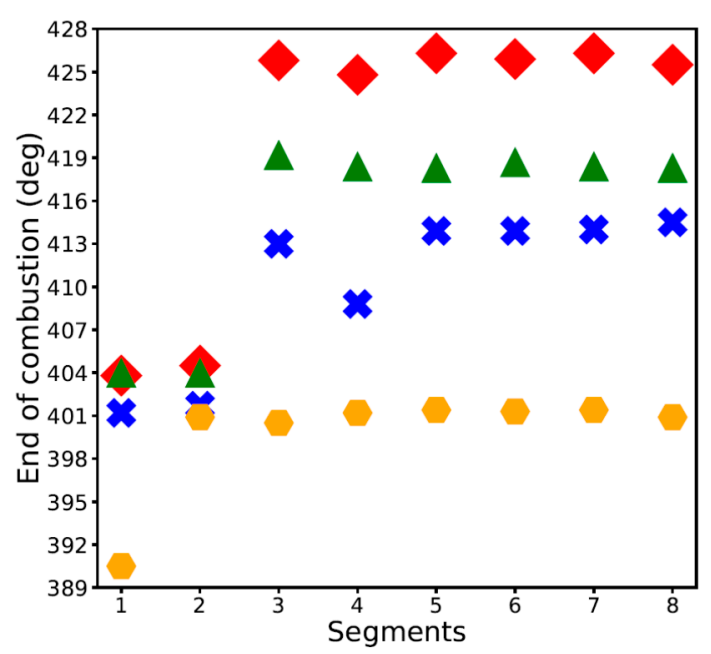

(a) $1500 \mathrm{rpm}$

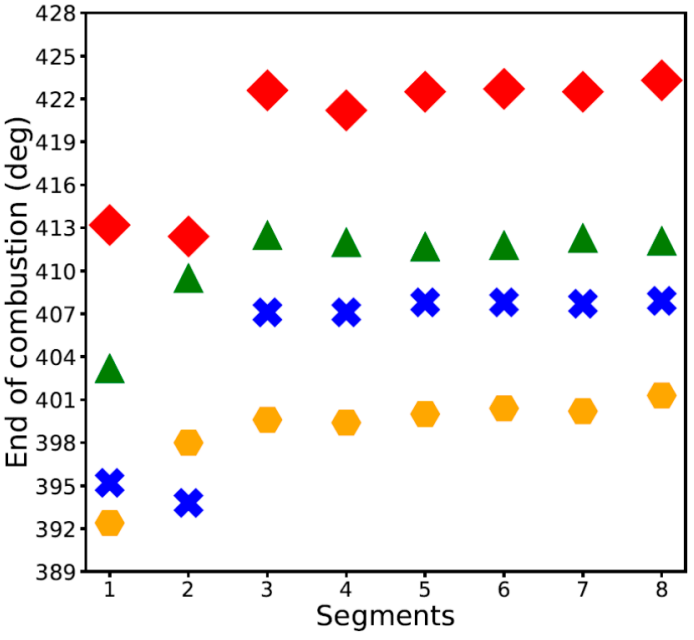

(b) $2000 \mathrm{rpm}$

Figure 12. End of combustion at all loads in each stage at (a) $1500 \mathrm{rpm}$ and (b) $2000 \mathrm{rpm}$. The red thick diamond represents $100 \%$ load, the blue thick cross $50 \%$ load, the green triangle $75 \%$ load and the orange hexagon $25 \%$ load.

\subsubsection{Combustion Duration}

During Stage 1, the engine was running an advanced injection strategy, with an increased ignition delay to enhance mixing. To produce higher in-cylinder pressure and temperature during Stage 1, rapid combustion was required, and therefore, the combustion duration during this stage was shorter. Although the combustion behaviour was expected to improve, as the engine coolant temperature increased from approximately $45^{\circ} \mathrm{C}$ in Segment 1 to $60{ }^{\circ} \mathrm{C}$ in Segment 2, it was most likely due to the cyclic variations in this stage that caused the mean combustion duration to vary approximately between $\pm 3 \%$. Figure 13a,b show the combustion duration at each load in the different stages of the custom cycle, at both engine speeds, $1500 \mathrm{rpm}$ and $2000 \mathrm{rpm}$.

During Stage 2, the injection was retarded in Segment 3, and it was observed that there was an increase of approximately $10 \%$ to $26 \%$ and $2 \%$ to $13 \%$ in the combustion duration at $1500 \mathrm{rpm}$ and $2000 \mathrm{rpm}$, respectively. The variation in the combustion duration between Stages 2 and 3 was approximately $\pm 2 \%$. The combustion duration during Stage 4 between Segments 6 and 7 and between Stages 3 and 4 varied approximately by $\pm 0.5 \%$ to $\pm 1 \%$.

It was observed that the combustion duration of each load in Segment 1 at $1500 \mathrm{rpm}$ was shorter than at $2000 \mathrm{rpm}$. This could have happened since $1500 \mathrm{rpm}$ was the engine speed for rated torque, and to fulfil the engine's requirement of achieving higher torque, shorter combustion durations were desirable. The most likely reason for the shorter combustion duration at $1500 \mathrm{rpm}$ in Stage 1 could have been due to less fuel being supplied at a lower engine speed, which could have led to relatively poor injection and combustion. The smaller combustion duration at $1500 \mathrm{rpm}$ could have also led to higher combustion rates and higher flame velocities, consequently leading to higher AHRR, as shown in Figures 5-8. Comparatively, during Stage 1 at $2000 \mathrm{rpm}$, a larger part of the fuel seems to have been burnt in the diffusion combustion mode, as significantly longer combustion durations were observed at all loads. It is quite possible that the ECU could have strategized to have longer combustion durations at $2000 \mathrm{rpm}$ to make more ignition sources available, due the availability of more fuel at all loads during Stage 1 at $2000 \mathrm{rpm}$. Furthermore, the combustion durations at both engine speeds increased 
with the engine load in all stages, as richer fuel was used to maintain a higher engine load at the same speed [32], and an increased combustion duration would have ensured a higher mixture uniformity.

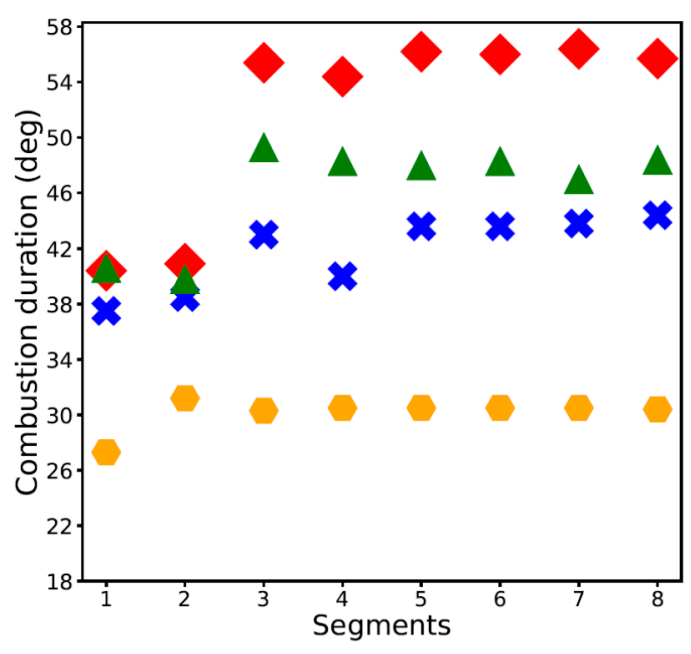

(a) $1500 \mathrm{rpm}$

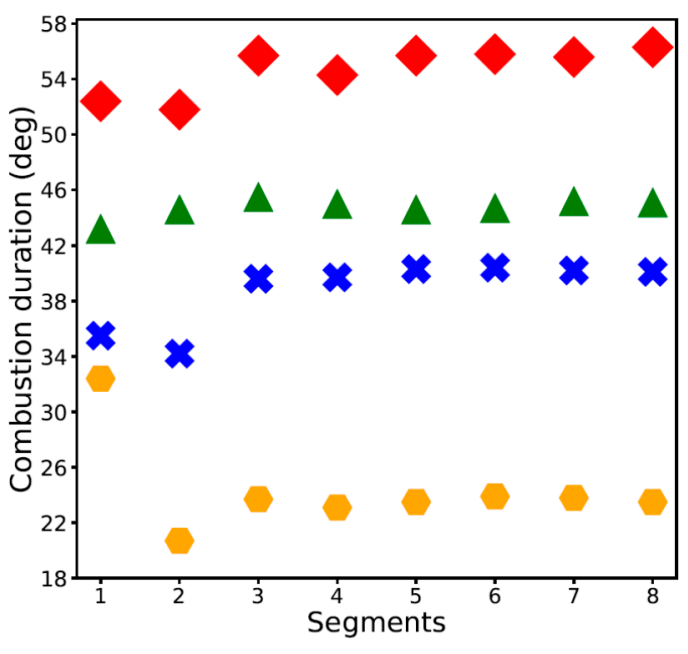

(b) $2000 \mathrm{rpm}$

Figure 13. Combustion duration at all loads in each stage at (a) $1500 \mathrm{rpm}$ and (b) $2000 \mathrm{rpm}$. The red thick diamond represents $100 \%$ load, the blue thick cross $50 \%$ load, the green triangle $75 \%$ load and the orange hexagon $25 \%$ load.

It was also observed that the percentage increase in the combustion durations from Stage 1 to 2 was higher at higher loads at $1500 \mathrm{rpm}$, with $100 \%$ and $75 \%$ loads showing an increase of approximately $26 \%$ and $19 \%$, respectively, while $50 \%$ and $25 \%$ loads showed an increase of $10 \%$ and $25 \%$, respectively. The most likely reason for that could be because a greater decrease in the pressure and temperature was required at higher loads than at lower loads, when the engine reached intermediate warm up in Stage 2 (Segment 3) at $1500 \mathrm{rpm}$.

Comparatively, the percentage increase in the combustion duration from Stage 1 to 2 at $2000 \mathrm{rpm}$ was approximately $2 \%$ to $7 \%$ at $100 \%$ and $75 \%$ loads, respectively, whereas at $50 \%$ and $25 \%$ loads, it was approximately $13 \%$, which could be due to the reason that a greater decrease in the in-cylinder pressure and temperature were required at lower loads, rather than at higher loads. An exception to the combustion duration behaviour was observed at $25 \%$ load at $2000 \mathrm{rpm}$, where the combustion duration decreased when the injection was retarded in Stage 2. The decrease in the combustion duration was also complimented with a longer ignition delay, as discussed in Section 3.6.1, where the most likely consequences of achieving mixture uniformity and higher in-cylinder pressure are discussed.

\subsubsection{CA50}

During Stage 1, the CA50 at all loads were observed to have occurred earlier because of the shorter combustion duration in this stage. This could have been a consequence of the rapid combustion during Stage 1, which was required to produce higher in-cylinder pressure and temperature. During Stage 1, the CA50 varied between Segments 1 and 2 by approximately $\pm 0.2 \%$. Figure $14 a$,b show the CA50 at each load in all stages of the custom cycle, at $1500 \mathrm{rpm}$ and $2000 \mathrm{rpm}$. As the combustion duration increased in Stage 2 due to injection retard, the CA50 was observed to have occurred later, as compared to Stage 1 . The CA50 increased by approximately $2 \%$ to 3\% from Stage 1 to 2 . During Stage 3 and 4 , the CA50 remained consistent and showed insignificant variations of approximately $0.1 \%$, since the $\mathrm{SOI}$ and combustion duration remained consistent in these stages. 


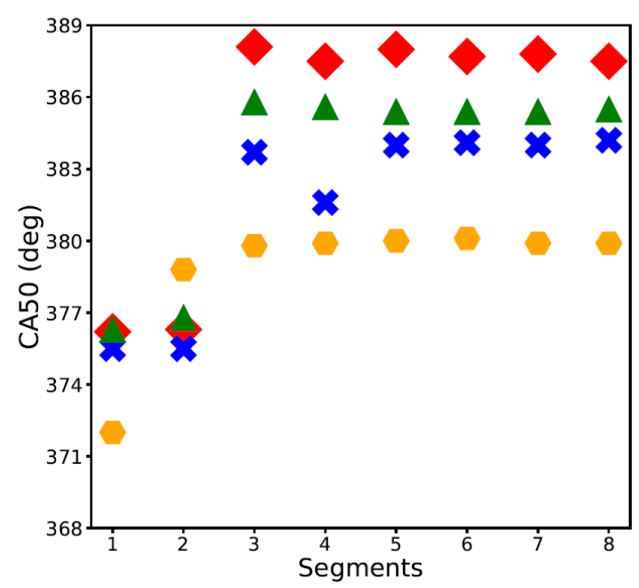

(a) $1500 \mathrm{rpm}$

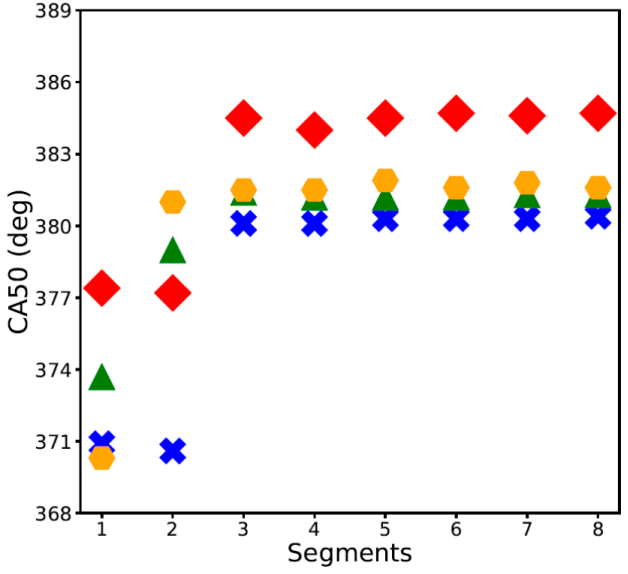

(b) $2000 \mathrm{rpm}$

Figure 14. CA50 at all loads in each stage at (a) $1500 \mathrm{rpm}$ and (b) $2000 \mathrm{rpm}$. The red thick diamond represents $100 \%$ load, the blue thick cross $50 \%$ load, the green triangle $75 \%$ load and the orange hexagon $25 \%$ load.

\subsubsection{AHRR@CA50}

Figure 15a,b show the AHRR@CA50 at each load in all stages of the custom cycle, at 1500 and $2000 \mathrm{rpm}$. During Stage 1, the AHRR at CA50 was initially lower, due to the low temperature of the in-cylinder environment. However, it increased as the engine temperature increased. During this stage, the AHRR at CA50 increased approximately by $1 \%$ to $5 \%$ at $2000 \mathrm{rpm}$, from Segments 1 to 2, as the engine coolant temperature increased from $25^{\circ} \mathrm{C}$ to $45^{\circ} \mathrm{C}$ in Segment 1 and $50{ }^{\circ} \mathrm{C}$ to $60^{\circ} \mathrm{C}$ in Segment 2, except for $25 \%$ load, where the AHRR decreased in Segment 2, when the injection strategy was retarded. This was an exceptional combustion behaviour observed, where the AHRR at CA50 decreased by approximately $27 \%$ in Stage 2 and onward. This could be due to the advancement of the whole combustion process, which made the combustion slower, with most of the combustion likely occurring late in the diffusion combustion mode, thereby reducing the AHRR at CA50, the peak AHRR and the peak pressure $[2,7]$.

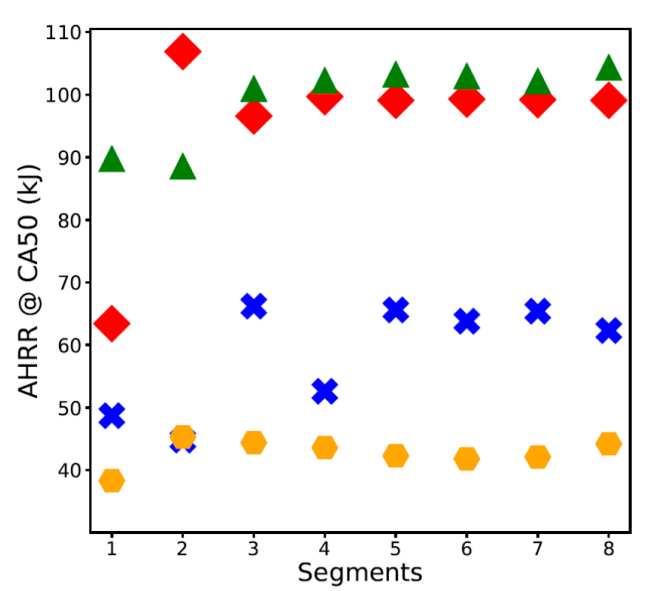

(a) $1500 \mathrm{rpm}$

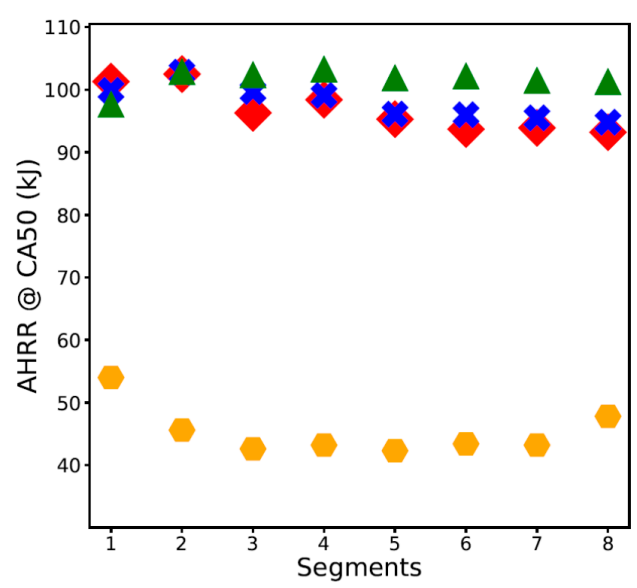

(b) $2000 \mathrm{rpm}$

Figure 15. AHRR at all loads in each stage at (a) $1500 \mathrm{rpm}$ and (b) $2000 \mathrm{rpm}$. The red thick diamond represents $100 \%$ load, the blue thick cross $50 \%$ load, the green triangle $75 \%$ load and the orange hexagon $25 \%$ load. 
Moreover, an increase in the AHRR at CA50 of approximately $10 \%$ to $35 \%$ occurred at $1500 \mathrm{rpm}$, while a decrease of approximately $5 \%$ to $25 \%$ in the AHRR at CA50 occurred at $2000 \mathrm{rpm}$, when Stage 2 was compared to Stage 1 . Therefore, it seems that at $1500 \mathrm{rpm}$, the AHRR at CA50 was not affected by the retarded injection strategy during this stage (Segment 3), which led to a decrease in the peak AHRR. Rather, it was affected by the engine temperature and increased further as the engine coolant and oil warmed up in Stage 3. It remained consistent thereafter in Stage 4. However, the injection strategy seems to have played a dominating role at $2000 \mathrm{rpm}$ and caused the AHRR at CA50 to decrease with the retarded injection. During Stage 4 , the AHRR at CA50 approximately varied by $\pm 4 \%$ at $1500 \mathrm{rpm}$ and \pm 1 at $2000 \mathrm{rpm}$ between Segments 6 and 7 .

\subsubsection{CA10-90}

The CA10-90 is a measure of the combustion duration, as a longer combustion duration increases CA10-90. CA10-90 showed the same trend as the combustion duration during the various stages of engine warm up, which is discussed in Section 3.6.2 and therefore not repeated in this section. Figure 16a,b show the CA10-90 at each load in all stages of the custom cycle, at $1500 \mathrm{rpm}$ and $2000 \mathrm{rpm}$. However, the duration (CA10-90) was approximately $50 \%$ of the combustion duration, at all loads, in all stages of engine warm up, which is indicative of $90 \%$ of the combustion completing in approximately $50 \%$ of the total combustion duration. Therefore, it seems that in the current study, the remaining $10 \%$ of the mixture was burnt in the latter half (approximately $50 \%$ duration) of the combustion duration in a late combustion phase, where the heat release continued at a lower rate [2,7]. This part of the combustion duration in a late combustion phase is utilised to burn the remaining fuel or oxidise the unburned $\mathrm{HC}$ or soot present in the combustion products [2,7].

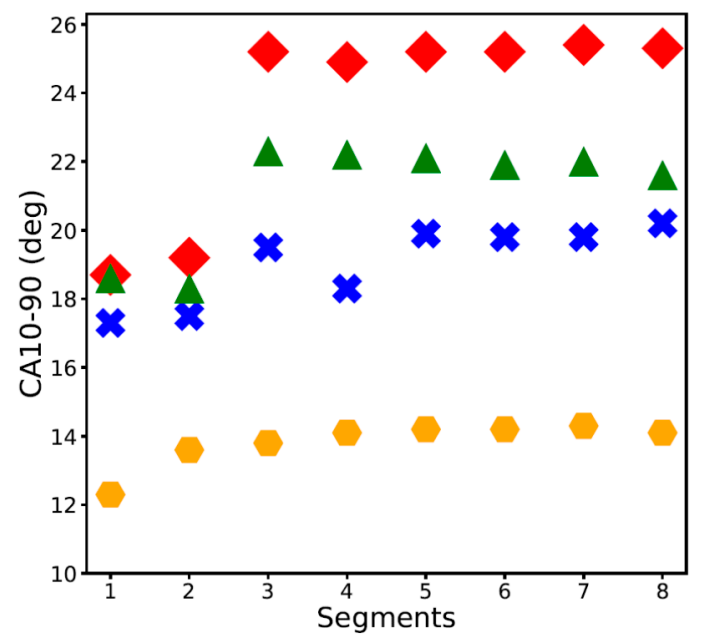

(a) $1500 \mathrm{rpm}$

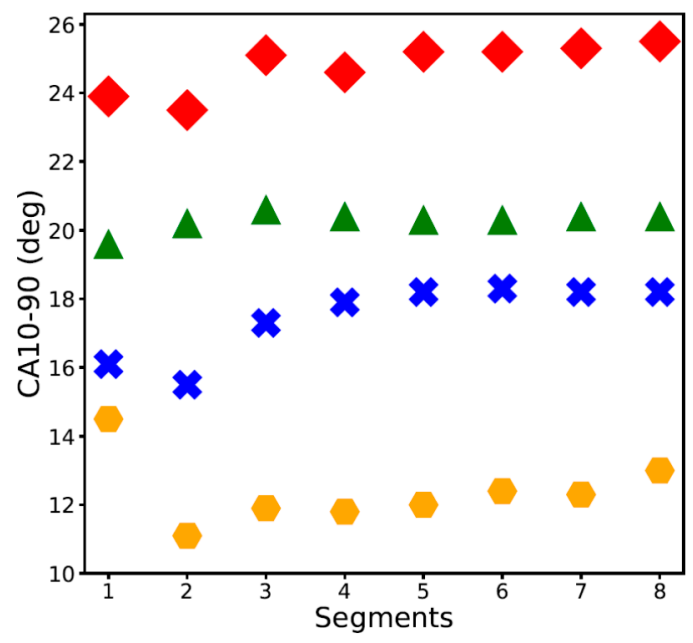

(b) $2000 \mathrm{rpm}$

Figure 16. CA10-90 at all loads in each stage at (a) $1500 \mathrm{rpm}$ and (b) $2000 \mathrm{rpm}$. The red thick diamond represents $100 \%$ load, the blue thick cross $50 \%$ load, the green triangle $75 \%$ load and the orange hexagon $25 \%$ load.

\section{Conclusions}

The current study offers a comprehensive analysis of a heavy-duty diesel engine combustion behaviour during cold, intermediately cold, warm and hot start operation, over a custom designed drive cycle. The drive cycle consisted of eight engine run segments of $120 \mathrm{~s}$ each, with a 60-s engine stop period in between each segment. There were abrupt load changes in the drive cycle segment, from high to low and vice versa, with the engine reaching a few seconds of quasi-steady-state operation at each load. The engine warm up was discretised into four stages, based on the coolant and oil warm 
up, to analyse the effects of the different stages of engine warm up on the engine combustion behaviour in the current study. Listed below are the main conclusions:

1. An advanced injection strategy was followed during the engine cold start period in Stage 1 (Segments 1 and 2), which led to longer ignition delays, shorter combustion durations, higher peak in-cylinder pressure and temperature and higher peak AHRR, consequently leading to a faster warm up.

2. The injection strategy was retarded in Stage 2, leading to shorter ignition delays, longer combustion durations, lower peak in-cylinder pressure and temperature and lower peak AHRR.

3. A reduction of approximately $25 \%$ to $30 \%$ and $15 \%$ to $20 \%$ in the peak pressure and approximately $2 \%$ to $5 \%$ and $\pm 1 \%$ in the peak AHRR was observed when the injection strategy was retarded in Segment 3.

4. The combustion parameters were seemed to be more influenced by the injection strategy, rather than the different stages of engine warm up.

5. The AHRR@CA50 decreased at 25\% load at 2000 rpm due to lower temperatures achieved with retarded injection, and therefore, a decrease in the combustion duration was observed to prevent any potential stalling of the engine.

6. The combustion parameters were more stable at $2000 \mathrm{rpm}$, rather than $1500 \mathrm{rpm}$, during all stages of engine run.

7. The COV of the IMEP values at each load in each segment was approximately less than $1 \%$.

Author Contributions: Conceptualization, F.L. and R.J.B.; Formal analysis, F.L. and T.B.; Investigation, F.L., A.Z., P.A., M.J., Z.R. and R.J.B.; Methodology, F.L., A.Z., P.A., S.S., Z.R., R.J.B. and T.B.; Project administration, S.S. and T.B.; Supervision, T.B.; Writing-original draft, F.L.; Writing-review \& editing, A.Z. and T.B. All authors have read and agreed to the published version of the manuscript.

Funding: This work was jointly funded by the School of Engineering at Deakin University and the Biofuel Engine Research Facility at Queensland University of Technology.

Acknowledgments: The authors express their gratefulness to Amir Moghaddam, Aaron Venn and Matthew Klaassen, the laboratory technical staff in the BERF at QUT for providing all the support needed to run this experimental campaign. The authors are also thankful to Caltex for donating the required diesel for this experimental campaign.

Conflicts of Interest: The authors declare no conflict of interest.

\section{References}

1. Government of Australia. Fossil Fuels_Department of Environment and Energy; Government of Australia: Canberra, Australia, 2017. Available online: https:/www.environment.gov.au/system/files/resources/ 7b9824b8-49cc-4c96-b5d6-f03911e9a01d/files/nggi-quarterly-update-dec-2017-revised.pdf (accessed on 10 February 2020).

2. Heywood, J.B. Internal Combustion Engine Fundamentals, International ed.; Automotive Technology Series; McGraw-Hill Book Company: Singapore, 1988; ISBN 9-780070-286375.

3. Palanisamy, M. Characteristics of Cold Start of a Diesel Engine Using Jp8 and Ulsd Fuels. Master's Thesis, Wayne State University, Detroit, MI, USA, 2013.

4. Rakopoulos, C.D.; Giakoumis, E.G. Diesel Engine Transient Operation: Principles of Operation and Simulation Analysis, 1st ed.; Springer: London, UK, 2009; ISBN 978-1-84882-375-4.

5. Henein, N.A. Autoignition and Combustion in Diesel Engines under Cold Starting Conditions; Report Number ARO 25190.2-EG; Wayne State University Centre for automotive research: Detroit, MI, USA, 1997.

6. Henein, N.A.; Zahdeh, A.R.; Yassine, M.K.; Bryzik, W. Diesel engine cold starting: Combustion instability. In SAE World Congress; SAE Technical Paper 920005; SAE: Warrendale, PA, USA, 1992. 
7. Stone, R. Introduction to Internal Combustion Engines; Palgrave Springer: London, UK, 1999; Volume 3, ISBN 978-0-333-55084-7.

8. Giakoumis, E.G.; Rakopoulos, C.D.; Dimaratos, A.M.; Rakopoulos, D.C. Exhaust emissions of diesel engines operating under transient conditions with biodiesel fuel blends. Prog. Energy Combust. 2012, 38, 691-715.

9. Liu, J.; Dumitrescu, C.E. Single and double Wiebe function combustion model for a heavy-duty diesel engine retrofitted to natural-gas spark-ignition. Appl. Energy 2019, 248, 95-103.

10. Yeliana, Y.; Cooney, C.; Worm, J.; Michalek, D.; Naber, J. Wiebe function parameter determination for mass fraction burn calculation in an ethanol-gasoline fuelled SI engine. J. KONES 2008, 15, 567-574.

11. Dhole, A.E.; Yarasu, R.B.; Lata, D.B. Investigations on the combustion duration and ignition delay period of a dual fuel diesel engine with hydrogen and producer gas as secondary fuels. Appl. Therm. Eng. 2016, 107, 524-532.

12. Ponti, F.; Serra, G.; Siviero, C. A phenomenological combustion model for common rail multi-jet diesel engine. In Proceedings of the ASME 2004 Internal Combustion Engine Division Fall Technical Conference, Long Beach, CA, USA, 24-27 October 2004.

13. Zhou, L.; Liu, Y.-F.; Wu, C.-B.; Sun, L.; Wang, L.; Zeng, K.; Huang, Z.-H. Effect of the diesel injection timing and the pilot quantity on the combustion characteristics and the fine-particle emissions in a micro-diesel pilot-ignited natural-gas engine. Proc. Inst. Mech. Eng. Part D J. Automob. Eng. 2013, 227, 1142-1152.

14. European Union Commission Directive. Commission Directive 2012/46/EU Official Journal of the European Union. 2012. Available online: https://eur-lex.europa.eu/LexUriServ/LexUriServ.do?uri=OJ:L:2012:353:0080: 0127:EN:PDF (accessed on 24 September 2019).

15. Jarrier, J.C.; Champoussin, R.; Gentile, D.Y. Warm-up of a D.I. diesel engine: Experiment and modeling. In SAE World Congress; SAE Technical Paper 2000-01-0299; SAE: Warrendale, PA, USA, 2000.

16. Giakoumis, E.G.; Dimaratos, A.M.; Rakopoulos, C.D. Experimental study of combustion noise radiation during transient turbocharged diesel engine operation. Energy 2011, 36, 4983-4995.

17. Bodisco, T.; Brown, R.J. Inter-cycle variability of in-cylinder pressure parameters in an ethanol fumigated common rail diesel engine. Energy 2013, 52, 55-65.

18. Brunt, M.F.; Pond, C.R. Evaluation of techniques for absolute cylinder pressure correction. In SAE World Congress; SAE Technical Paper 970036; SAE: Warrendale, PA, USA, 1997.

19. Randolph, A.L. Methods of processing cylinder-pressure transducer signals to maximize data accuracy. In SAE World Congress; SAE Technical Paper 900170; SAE: Warrendale, PA, USA, 1999.

20. Lodi, F.; Zare, A.; Arora, P.; Stevanovic, S.; Jafari, M.; Ristovski, Z.; Brown, R.J.; Bodisco, T. Engine Performance and Emissions Analysis in a Cold, Intermediate and Hot Start Diesel Engine. Appl. Sci. 2020, 10, 3839.

21. Zare, A.; Bodisco, T.A.; Nabi, M.N.; Hossain, F.M.; Ristovski, Z.D.; Brown, R.J. A comparative investigation into cold-start and hot-start operation of diesel engine performance with oxygenated fuels during transient and steady-state operation. Fuel 2018, 228, 390-404.

22. Srinivasan, K.K.; Krishnan, S.R.; Midkiff, K.C. Improving low load combustion, stability, and emissions in pilot-ignited natural gas engines. Proc. Inst. Mech. Eng. Part D J. Automob. Eng. 2006, 220, 229-239.

23. Bulatović, Ž.; Knežević, D.; Milić, M. Practical research of the angle of thermodynamic losses when indicating pressure in the cylinder diesel engine. Sci. Tech. Rev. 2015, 65, 46-54.

24. Pipitone, E.; Beccari, A.; Beccari, S. The experimental validation of a new thermodynamic method for TDC determination. In SAE World Congress; SAE Technical Paper 2007-01-0052; SAE: Warrendale, PA, USA, 2007.

25. Lodi, F.; Jafari, M.; Brown, R.; Bodisco, T. Statistical Analysis of the Results Obtained by Thermodynamic Methods for the Determination of TDC Offset in an Internal Combustion Engine. In SAE World Congress; SAE Technical Paper 2020-01-1350; SAE: Warrendale, PA, USA, 2020.

26. Lodi, F.; Bodisco, T.; Surawski, N.; Brown, R.; Yousef, Y. Modelling the effects of ethanol fumigation on engine performance and emissions in a six-cylinder, common rail diesel engine. In Proceedings of the 11th Asia-Pacific Conference on Combustion, ASPACC, Sydney, Australia, 10-14 December 2017; The Combustion Institute: Sydney, Australia, 2017.

27. Bodisco, T.; Low Choy, S.; Brown, R.J. A Bayesian approach to the determination of ignition delay. Appl. Therm. Eng. 2013, 60, 79-87. 
28. Bodisco, T.; Tröndle, P.; Brown, R.J. Inter-cycle variability of ignition delay in an ethanol fumigated common rail diesel engine. Energy 2015, 84, 186-195.

29. Hara, H.; Itoh, Y.; Henein, N.A.; Bryzik, W. Effect of cetane number with and without additive on cold startability and white smoke emissions in a diesel engine. In SAE World Congress; SAE Technical Paper 1999-01-1476; SAE: Warrendale, PA, USA, 1999.

30. Mendera, K.Z.; Spyra, A.; Smereka, M. Mass fraction burned analysis. J. KONES Int. Combust. Eng. 2002, 3, $193-201$.

31. Aklouche, F.Z.; Loubar, K.B.A.; Awad, S.T.M. Experimental investigation of the equivalence ratio influence on combustion, performance and exhaust emissions of a dual fuel diesel engine operating on synthetic biogas fuel. Energy Convers. Manag. 2017, 152, 291-299.

32. Yusri, I.M.; Mamat, R.; Akasyah, M.K.; Jamlos, M.F.; Yusop, A.F. Evaluation of engine combustion and exhaust emissions characteristics using diesel/butanol blended fuel. Appl. Therm. Eng. 2019, 156, 209-219.

(C) 2020 by the authors. Licensee MDPI, Basel, Switzerland. This article is an open access article distributed under the terms and conditions of the Creative Commons Attribution (CC BY) license (http://creativecommons.org/licenses/by/4.0/). 